\title{
FILTRAÇÃO EM MÚLTIPLAS ETAPAS (FIME) MODIFICADA POR MATERIAIS NÃO CONVENCIONAIS
}

\author{
MULTI-STAGE FILTRATION (FIME) MODIFIED BY UNCONVENTIONAL MATERIALS
}

Tiago Silva de Almeidaa ${ }^{a}$ Anderson de Jesus Lima ${ }^{a}$, Lucas de Araújo Souza ${ }^{a}$, Denise Conceição de Góis Santos Michelan ${ }^{a}$

aUniversidade Federal de Sergipe

tiiagotg@gmail.com, andersoncivil2014@gmail.com, lucasdeasouza@gmail.com, denise gois@yahoo.com.br

\section{Resumo}

Dentre as técnicas disponíveis para tratamento de água para abastecimento humano, pesquisas apontam a filtração em múltiplas etapas (FiME) como alternativa para algumas limitações da filtração lenta pelos tradicionais filtros de areia. Com o objetivo de amortecer picos de cor e turbidez da água afluente, a FiME propõe uma ou mais etapas de filtração antecedentes aos filtros lentos, podendo incorporar materiais não convencionais e resíduos na composição dos leitos filtrantes das suas etapas de filtração, agregando viés ambiental e econômico. Assim, o trabalho avaliou a eficiência do tratamento do sistema de FiME composto por três unidades de filtração ligadas em série, com meios filtrantes compostos por manta não tecida, resíduo de cerâmica vermelha e fibras de coco. O sistema piloto operou sob taxa de filtração de $3 \mathrm{~m}^{3} / \mathrm{m}^{2}$ dia $\pm 10 \%$, em regime intermitente, através de dois Estágios distintos (Estágios 1 e 2). O monitoramento do sistema, associado às análises estatísticas realizadas, não evidenciou diferenças significativas entre os desempenhos alcançados nos dois Estágios. Os pré-filtros apresentaram eficiências médias de remoção de cor aparente de $60 \%$ e $46 \%$ para os Estágios 1 e 2, respectivamente, ao passo em que a eficiência média de remoção de turbidez alcançada foi de $64 \%$ no Estágio 1 e $57 \%$ para o Estágio 2, baseando-se, sobretudo, na capacidade de adsorção dos resíduos cerâmicos. A adição das camadas de manta não tecida foi pouco expressiva sobre a eficiência dos filtros, entretanto pôde agregar estabilidade na operação destes, haja vista os baixos Índices de Decaimento da Qualidade da Água (IDQA) alcançados.

Palavras-chave: Filtração lenta; Pré-filtro; Resíduo cerâmico; Fibra de coco; Manta não tecida.

\section{Abstract}

Among the techniques available for water treatment for human supply, research points to multi-stage filtration (FiME) as an alternative to some limitations of slow filtration by traditional sand filters. In order to cushion peaks of color and turbidity of affluent water, FiME proposes one or more steps of filtration antecedent to slow filters, and may incorporate unconventional materials and residues in the composition of filter beds of its filtration stages, adding environmental and economic bias. Thus, the work evaluated the efficiency of the treatment of the FiME system composed of three filtration units connected in series, with filter media composed of unwoven blanket, red ceramic residue and coconut fibers. The pilot system operated under filtration rate of $3 \mathrm{~m}^{3} / \mathrm{m}^{2}$ day $\pm 10 \%$, in an intermittent regime, through two distinct stages (Stages 1 and 2 ). The monitoring of the system, associated with the statistical analyses performed, did not show significant differences between the performances achieved in the two Stages. The prefilters showed average apparent color removal efficiencies of $60 \%$ and $46 \%$ for Stages 1 and 2, respectively, while the average efficiency of turbidity removal achieved was $64 \%$ in Stage 1 and $57 \%$ for Stage 2, based mainly on the adsorption capacity of ceramic residues. The addition of the layers of unwoven blanket was little expressive about the efficiency of the filters, however it was able to add stability in the operation of these, given the low Water Quality Decay Indexes (IDQA) achieved.

Key-words: Slow filtration; Pre-filter; Ceramic residue; Coconut fiber; Unwoven blanket. 


\section{INTRODUÇÃO}

Segundo o World Water Assessment Programme - WWAP, que em português "Programa Mundial de Avaliação de Água" (WWAP, 2019), em 2015, aproximadamente 29\% da população mundial ainda não dispunha de serviços capazes de ofertar água potável de forma gerenciada e segura, enquanto outras 844 milhões de pessoas ainda não eram atendidas nem mesmo com os serviços mais básicos de água potável.

Nesse sentido, diante das variadas técnicas empregadas para o tratamento de água para abastecimento, os tradicionais filtros lentos de areia apresentam-se vantajosos, tendo em vista sua simplicidade de execução, baixo custo associado à operação e boa eficiência na remoção de microrganismos, cor e turbidez (DI BERNARDO; SABOGAL, 2008). No início de sua operação, os filtros lentos retêm as impurezas por causa do tamanho destas ser maior que os vazios existente entre os grãos do meio filtrante, seguida em menor escala pela adsorção. Entretanto, a partir do processo de amadurecimento do filtro, há formação da camada com significativa atividade biológica, schmutzdecke, que passa a ser a principal forma de remoção de partículas e microrganismos (ZHANG et al., 2018).

Embora diversos estudos, dentre os quais D'Alessio et al. (2016) e Tundia et al. (2016), apresentem bons resultados com aplicação dos filtros lentos, Lima (2020) defende que não é aconselhável apontar eficiências globais para esse tipo de tratamento, devido à forte influência exercida pelas particularidades de aplicação, como taxa de filtração, meio filtrante e qualidade da água bruta. Sendo assim, vale ressaltar que esses filtros apresentam limitações quanto à qualidade da água afluente, a exemplo valores relativamente baixos de cor, sólidos grosseiros (SILVEIRA; COUTINHO, 2016) e turbidez limitada em 10 uT (VERAS; DI BERNARDO; SABOGAL, 2008).

Como alternativa às limitações da filtração lenta $(F L)$ quanto à qualidade da água afluente, a Filtração em Múltiplas Etapas (FiME) propõe uma ou mais etapas de tratamento que antecedem a $\mathrm{FL}$, sendo composta, geralmente, por pré-filtro dinâmico, pré-filtro de pedregulho e filtros lentos de areia. As etapas de pré-filtro dinâmico e a de préfiltro de pedregulho, podem apresentar uma ou mais unidades, além de meio filtrante com granulometria específica utilizando camadas estratificadas ou camada única (CLARKE et al., 2004; TANGERINO et al., 2013; MACHADO et al., 2016).

Sendo assim, com possibilidade para alternativas de pré-tratamento, a FiME apresentase com potencial a superar as limitações da FL (VERAS; DI BERNARDO, 2008), de forma que seja possível promover a redução de parâmetros físico e químicos, como cor, turbidez e sólidos grosseiros (DISA-DISA et al., 2014; SILVEIRA; COUTINHO, 2016), além da remoção de microrganismos (MENDONZA et al., 2019), substâncias húmicas (TANGERINO; DI BERNARDO, 2005) e algas presentes na água bruta ( TANGERINO et al., 2001; TANGERINO et al., 2013). Para tanto, a técnica de FiME pode ainda incorporar materiais de diversas origens para compor o meio filtrante de suas etapas de filtração, a exemplo de materiais não convencionais e resíduos agroindustriais, como as fibras de coco, resíduos cerâmicos e maravalha (NUNES; LIMA; MICHELAN, 2018; SANTOS JUNIOR et al., 2020).

Concernente à utilização de materiais não convencionais, a utilização de mantas não tecidas sobre o leito filtrante traz como benefícios a possibilidade de prolongar duração das carreiras de filtração e auxiliar na redução de parâmetros físicos e químicos (SANTOS, 2015), bem como proporcionar a redução da espessura do meio filtrante (DI BERNARDO; SABOGAL PAZ, 2008). Além disso, a utilização da manta favorece a formação da camada biológica, sem que haja necessidade de posterior raspagem superficial para a limpeza do filtro, bastando apenas retirar a manta, lavá-la e reutilizá-la (VERAS; DI BERNARDO, 2008).

Por outro lado, os resíduos cerâmicos, quando utilizados em pré-filtros para redução de picos de turbidez, mostraram-se capazes de proporcionar melhorias na água de estudo, apresentando-se como alternativa viável ao uso dos tradicionais seixos (RAJAPAKSE; FENNER, 2011), promovendo eficiências de remoção acima de 70\% para amostras com até 600 UT (JAYALATH et al., 2016).

Além disso, no que diz respeito às fibras de coco, estas se mostraram duráveis quando imersas em água (SILVA et al., 2015), promovendo a liberação de tanino, substância com potencial coagulante (PERONI et al., 2019), interessante às atividades relacionadas ao tratamento de água. As fibras também mostraram-se eficientes quando 
aplicadas aos tratamentos de águas residuárias, agindo frente à redução de efluentes oleosos (ALMAGRO; ROCHA, 2015) e metais pesados (SOUSA et al., 2007).

Em se tratando da indústria do coco, o Brasil já alcançou a produção de cerca de $80 \%$ do coco de toda a América do Sul (SIMONETTI et al., 2017), ocupando a quinta posição no ranking mundial de produção do coco e área cultivada, ficando atrás da Indonésia, Filipinas, Índia e Sri Lanka (BRAINER, 2018). Contudo, a geração de resíduos por essa cultura é proporcional à sua produção, podendo gerar custos e se transformar em problema de ordem ambiental (SILVA et al., 2015). Haja vista o tempo para sua degradação, podendo ocorrer em até oito anos (SIMONETTI et al., 2017), além da disposição realizada, de modo geral, em aterros sanitários e lixões (CARDOSO; GONÇALEZ, 2016).

Paralelamente, estudos realizados por Garcia et al. (2014), baseados em informações divulgadas pela Associação Nacional da Indústria Cerâmica (ANICER) para o ano de 2014, estimaram a geração de resíduo de cerâmica vermelha (RCV) variando entre 3,9 e 6,5 milhões de toneladas, como consequência de produtos danificados ainda na indústria. Contudo, cabe ressaltar que a estimativa supracitada não considerou os resíduos cerâmicos gerados pela indústria da construção civil, inferindo que os valores apresentados são ainda maiores.

Sendo assim, considerando as vantagens da utilização de materiais não convencionais, sobretudo resíduos, e os ganhos obtidos com a utilização de FiME, no que diz respeito aos requisitos de qualidade de água, o presente estudo avaliou a eficiência de um sistema de filtração em múltiplas etapas com meios filtrantes compostos por manta não tecida, resíduo de cerâmica vermelha e fibras de coco, através do monitoramento e análises de parâmetros físicos e químicos.

\section{METODOLOGIA}

\section{Instalação piloto e água de estudo}

$O$ aparato experimental de FiME denominado de sistema piloto foi composto por uma bomba periférica, dois reservatórios e três tubos cilíndricos de Policloreto de Vinila (PVC) dispostos verticalmente e ligados em série.

A água de estudo utilizada para alimentar os filtros foi sintetizada (adição de 10\% de esgoto bruto em água subterrânea), denominada água bruta ( $A B)$. Esta água foi armazenada em um reservatório apoiado (R1), e posteriormente bombeada para um reservatório elevado (R2), com base à cota de aproximadamente $2,50 \mathrm{~m}$, a fim de garantir que 0 escoamento para os filtros ocorresse exclusivamente por gravidade. O transporte da água do R1 para o R2 ocorreu através do acionamento da bomba com potência de $0,5 \mathrm{CV}$ e vazão máxima de $40 \mathrm{~L} / \mathrm{min}$.

O R2 possuía dispositivo regulador de nível d'água (boia), para garantir a carga hidráulica constante, além disso, dispunha ainda de torneira para auxiliar no monitoramento e ajustes de vazão, na ordem de $1 \times 10^{-3} \mathrm{~m}^{3} / \mathrm{h}$ na saída do reservatório, a fim de promover taxa de filtração constante e igual a $3 \mathrm{~m}^{3} / \mathrm{m}^{2}$ dia $\pm 10 \%$ (em todo o estudo ocorreram 114 aferições), com regime de operação para o sistema de FiME intermitente.

Nesse sentido, o sistema de FiME foi composto por três unidades de filtração funcionando em série, sendo a primeira o pré-filtro com leito filtrante de resíduo cerâmico (PFRC), seguido por dois filtros lentos com camada suporte de brita 3/4" e leito filtrante composto por fibras de coco. Os dois últimos divergem entre si quanto ao sentido do escoamento, em que o primeiro dispunha de escoamento ascendente (FFCA) e o segundo de escoamento descendente (FFCD). Ademais, todas as unidades supracitadas possuíam altura de $50 \mathrm{~cm}$ e $10 \mathrm{~cm}$ de diâmetro, totalizando volume útil de aproximadamente 3,9 $\times 10^{-3} \mathrm{~cm}^{3}$ e foram dotadas de dispositivo para descarga de fundo. A Figura 1 apresenta de forma esquematizada o sistema proposto.

Por fim, considerando a composição dos meios filtrantes e o período de operação do sistema, foi possível estabelecer estágios distintos para o experimento: Estágio 1 e Estágio 2. O Estágio 1 abrangeu 27 dias de coletas, enquanto que o Estágio 2 englobou 30 dias, o que significa que, das amostras coletadas para determinação dos parâmetros, foram 27 dados para cada parâmetro referente ao Estágio 1, enquanto que, para o Estágio 2 foram 30 dados referentes para cada parâmetro estudado.

No Estágio 1, consideradas as nomenclaturas das etapas compreendidas pelo sistema, que vão desde a água bruta $(A B)$ até o filtro com fibra de coco de escoamento descendente, todas receberam o sufixo "1", a fim de referenciar a etapa do sistema de filtração ao Estágio abordado. Nesse sentido, o pré-filtro de resíduos cerâmicos 
triturados do Estágio 1 (PFRC1) teve seu leito filtrante uniforme com espessura de $28 \mathrm{~cm}$, onde 0 material utilizado apresentou relação $D_{\text {máx }} / D_{\text {mín }}=$ 3,30 e ocupou o volume de $2,2 \times 10^{-3} \mathrm{~cm}^{3}$.

Por outro lado, os filtros lentos seguintes ao PFRC1 dispunham de camada suporte com espessura total de seis centímetros, composta por britas 3/4", enquanto seus leitos filtrantes uniformes possuíam espessura de $16 \mathrm{~cm}$ e foram compostos por fibras de coco não alinhadas. Para tanto, o filtro com fibra de coco de escoamento ascendente do Estágio 1 (FFCA1), imediatamente após o PFRC1, recebeu 231,07 g de fibras para composição do seu leito filtrante, enquanto o filtro com fibra de coco de escoamento descendente (FFCD1) recebeu 241,64 g de fibras.

Figura 1: Esquema construtivo do sistema de Filtração em Múltiplas Etapas

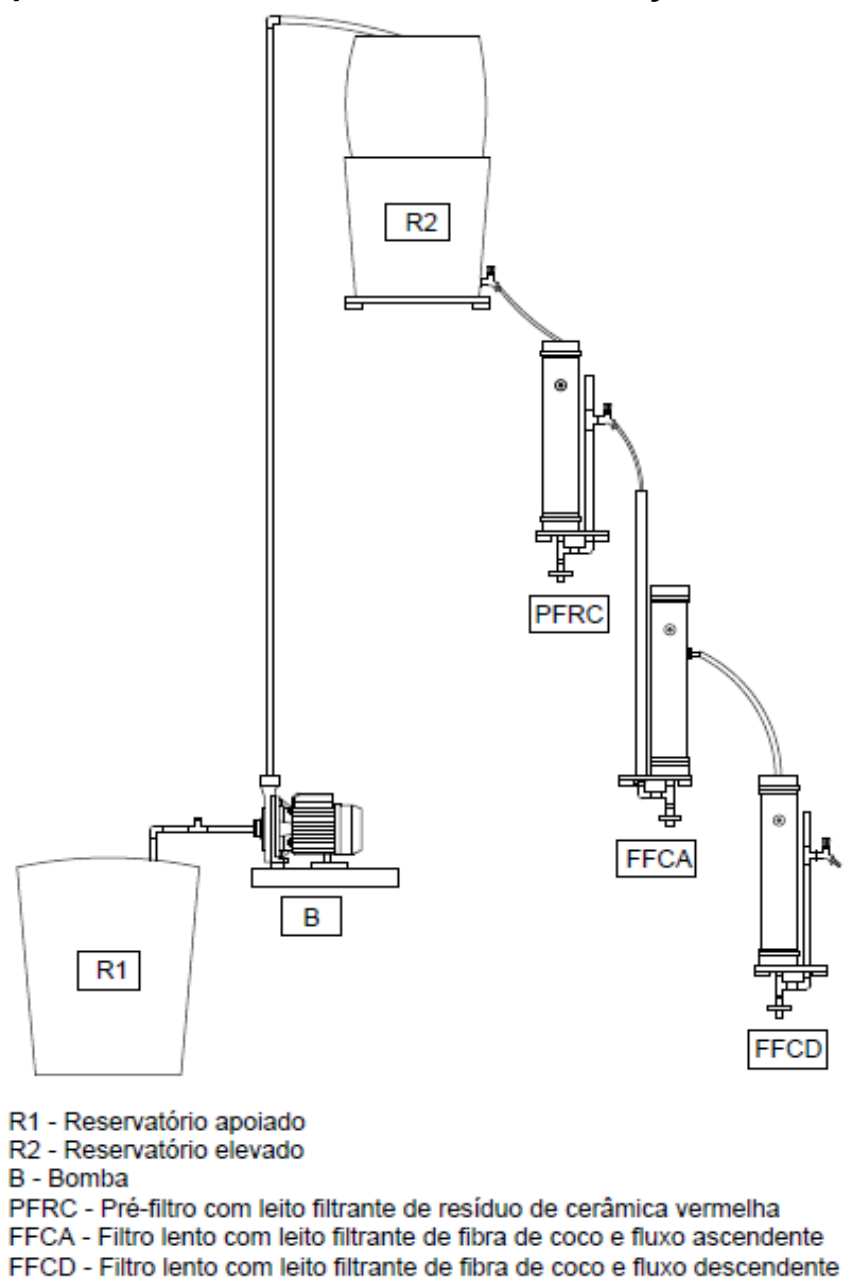

Fonte: Autores (2021).

O Estágio 2 teve início após o término do Estágio 1 e toda a configuração do sistema de FiME apresentada no primeiro Estágio foi preservada. Contudo, os materiais que compõem os leitos filtrantes foram retirados e lavados.

Além disso, os filtros lentos com leitos filtrantes de fibras de coco receberam adição de três camadas de manta não tecida, sobrepostas entre si, e depositadas diretamente no topo dos seus respectivos leitos filtrantes, de modo a verificar possíveis melhorias no efluente do sistema promovidas pela adição das camadas de manta.

Ademais, semelhantemente ao Estágio 1, todas as etapas compreendidas pelo sistema receberam o sufixo "2", cujo intuito foi evidenciar as alterações realizadas nos leitos filtrantes, bem como associar a etapa do sistema ao referido Estágio. Para tanto, o pré-filtro com leito filtrante de resíduo cerâmico no Estágio 2 (PFRC2), embora não tenha recebido adição de manta, também recebe o sufixo indicador do presente estágio. 
Nesse sentido, os filtros lentos com leito filtrante de fibra de coco no Estágio 2, tanto o de escoamento ascendente (FFCA2) quanto o de escoamento descendente (FFCD2), foram monitorados e avaliados conforme desempenho alcançado pela combinação das fibras de coco com as camadas de manta não tecida.

\section{Materiais do leito filtrante}

As fibras de coco utilizadas como meio filtrante foram oriundas da fruta coco e formadora da camada mesocarpo (também denominado de feixe de fibras). As fibras de cocos foram submetidas à lavagem em duas etapas: água corrente com lavagens consecutivas da fibra, até que a água de lavagem não apresentasse coloração excessiva perceptível visualmente; posteriormente consistiu na imersão da fibra em água destilada com troca de água a cada 24 horas, até que a descoloração da fibra apresentasse redução visual, seguida de exposição à temperatura ambiente para secagem natural antes da aplicação aos filtros.

Considerando a quantidade de fibra utilizada nesses filtros, como exposto anteriormente, podese estabelecer que FFCA1 = FFCA2 e FFCD1 = FFCD2 e as respectivas densidades de aplicação podem ser observadas na Tabela 1. Não se caracterizou as fibras de coco quanto ao tamanho efetivo e coeficiente de uniformidade, como normalmente ocorre com 0 meio filtrante empregado nos filtros lentos, porque as fibras foram utilizadas respeitando o seu comprimento natural, o qual não se assemelha a grão.

Tabela 1: Densidade de ocupação das fibras de coco como meio filtrante

\begin{tabular}{ccc} 
& FFCA1 e FFCA2 & FFCD1 e FFCD2 \\
\hline Quantidade de fibra $(\mathbf{g})$ & 231,07 & 241,64 \\
Volume ocupado $\left(\mathbf{c m}^{3}\right)$ & $1,26 \times 10^{3}$ & $1,26 \times 10^{3}$ \\
Densidade de aplicação $\left(\mathbf{g} / \mathbf{c m}^{3}\right)$ & 0,18 & 0,19 \\
\hline
\end{tabular}

Fonte: Autores (2021).

Os resíduos de cerâmica vermelha utilizados foram coletados em depósitos temporários dos resíduos de construção e demolição (RCD), livres de eventuais impurezas aderidas, como argamassas de cimento, gesso e resquícios de produtos químicos. Além do mais, foi dada preferência para resíduos de blocos cerâmicos, por predominarem em meio aos detritos.

Os resíduos cerâmicos foram processados em triturador e, em seguida, foi realizado $O$ quarteamento da amostra (ASSOCIAÇÃO BRASILEIRA DE NORMAS TÉCNICAS, 2004). Ainda, a fim de reduzir ao máximo a possibilidade de impurezas aderidas ao material triturado, este foi exposto à água corrente, até que a água de lavagem não apresentasse coloração excessiva visualmente perceptível. Em seguida, o material foi exposto à temperatura ambiente para a secagem natural antes da aplicação ao filtro. Além disso, a caracterização granulométrica foi realizada por meio de paquímetro digital, possibilitando obter a relação $D_{\text {máx }} / D_{\min }$ da direção considerada (Tabela 2). Em observação ao diâmetro máximo $\left(D_{\text {máx }}\right)$ e diâmetro mínimo $\left(D_{\min }\right)$, como se refere ao tamanho do resíduo cerâmico, o mesmo apresenta tamanhos maiores que os tamanhos recomendados para a areia, comumente utilizada nos filtros lentos (ABNT, 1992).

A manta geotêxtil utilizada foi do tipo não tecida, produzida com fibras cortadas em poliéster, agulhadas e consolidada termicamente por calandragem. As características da manta estão apresentadas no Quadro 1

Tabela 2: Descrição do resíduo cerâmico triturado

\begin{tabular}{cccccc}
\hline $\begin{array}{c}\text { Média } \\
(\mathbf{m m})\end{array}$ & $\begin{array}{c}\text { Mediana } \\
(\mathbf{m m})\end{array}$ & $\begin{array}{c}\text { Desvio } \\
\text { Padrão }\end{array}$ & $\begin{array}{c}\mathbf{D}_{\text {máx }} \\
(\mathbf{m m})\end{array}$ & $\begin{array}{c}\mathbf{D}_{\text {min }} \\
(\mathbf{m m})\end{array}$ & $\mathbf{D}_{\text {máx }} / \mathbf{D}_{\text {min }}$ \\
\hline 22,52 & 20,93 & 7,40 & 42,89 & 11,58 & 3,30 \\
\hline
\end{tabular}

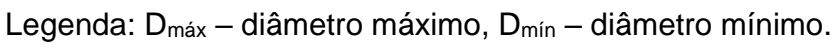

Fonte: Autores (2021). 


\section{Quadro 1: Características da manta geotêxtil não tecida}

\begin{tabular}{|cc|}
\hline \multicolumn{2}{|c|}{ Características físicas } \\
\hline Gramatura $\left(\mathrm{g} / \mathrm{m}^{2}\right)$ & 150 \\
Espessura $(\mathrm{mm})$ & 1,2 \\
Ponto de amolecimento $\left({ }^{\circ} \mathrm{C}\right)$ & 230 a 249 \\
Resistência U.V $(\% /$ horas $)$ & $50 / 500$ \\
Cor & Preta \\
\hline Características hidráulicas \\
\hline Permeabilidade normal $(\mathrm{cm} / \mathrm{s})$ & 0,23 \\
Permissividade $\left(\mathrm{s}^{-1}\right)$ & 1,7 \\
Velocidade do fluxo $(\mathrm{m} / \mathrm{s})$ & 0,10 \\
Abertura aparente $(\mathrm{AOS})(\mathrm{mm})$ & 0,075 \\
\hline
\end{tabular}

Fonte: MACCAFERRI (2019).

\section{Análise da água bruta e filtrada}

Foi realizado monitoramento da água bruta e filtrada, além da água após cada filtro, cinco dias por semana e conforme parâmetros apresentados pelo Quadro 2, que expõe também as metodologias e equipamentos utilizados.

Foram realizadas análises estatísticas referentes aos valores apresentados no monitoramento (processados com nível de significância de $5 \%$ ), análises de eficiência quanto à remoção do parâmetro, Índice de Atendimento ao Padrão de Potabilidade (IAPP) e Índice de Decaimento da Qualidade da Água (IDQA), citados em Lima (2020). O IAPP é a Relação entre o número de amostras, de um referido parâmetro, que atenderam ao padrão de potabilidade do Ministério da Saúde (MS) e o número total de amostras, para o mesmo parâmetro, em percentual. Já o IDQA é a Relação entre o número de amostras que apresentaram piora da qualidade da água, para um referido parâmetro, e o número total de amostras do mesmo parâmetro, em percentual.

Ademais, com o objetivo de agregar maior confiabilidade aos resultados, os valores obtidos foram analisados conforme teste de normalidade, através do teste de Shapiro-Wilk, e posterior aplicação de testes estatísticos paramétrico e não paramétrico. Este foi utilizado quando não verificadas adequações dos resultados à distribuição normal, ou ainda quando necessário comparar variáveis com distribuições normal e não-normal, enquanto aquele, por sua vez, foi utilizado apenas em casos de atendimento à distribuição normal.

\section{Parâmetros de estudo e respectivos limites adotados}

No que diz respeito à água tratada $e$ destinada ao consumo humano, é imprescindível atentar-se aos padrões de potabilidade instituídos pelo Gabinete do Ministro (GM) do Ministério da Saúde (MS), através da Portaria de Potabilidade ${ }^{\circ}$ 888 (BRASIL, 2021). Dos parâmetros analisados nesse estudo, a referida Portaria, apresenta o valor máximo permitido (VMP) para os parâmetros de estudo (cor aparente, turbidez e pH). O Quadro 3 expõe o VMP instituído pelo MS.

Para mais, embora o padrão de potabilidade do MS permita valores de até 5,0 UT para água tratada na rede de distribuição, a exigência para a água efluente aos filtros lentos torna-se mais restritiva, sendo tolerado até 1,0 UT (BRASIL, 2021). Sendo assim, em concordância ao MS, o presente estudo adotou turbidez de até 1,0 UT como parâmetro a ser atendido pela água filtrada.

Quadro 2: Parâmetros analisados

\begin{tabular}{|ccc|}
\hline Parâmetro & Unidade & Metodologia/Equipamento \\
\hline Cor aparente & $(\mathrm{uC})$ & Metodologia 2120 (APHA, 2012)/Espectrofotômetro \\
\hline Turbidez & $(\mathrm{UT})$ & Metodologia 2130 (APHA, 2012)/Espectrofotômetro \\
\hline $\mathrm{pH}$ & - & Metodologia 4500-H (APHA, 2012) /pHmetro \\
\hline Temperatura & $\left({ }^{\circ} \mathrm{C}\right)$ & Termômetro de Infravermelho \\
\hline
\end{tabular}

Fonte: Autores (2021). 
Quadro 3: Parâmetros utilizados

\begin{tabular}{|ccc|}
\hline Parâmetro & Unidade & VMP \\
\hline Cor aparente & uH & 15 \\
Turbidez & uT & 1,0 \\
pH & - & 6,0 a 9,5 \\
\hline
\end{tabular}

Fonte: Adaptado de Brasil (2021).

\section{RESULTADOS E DISCUSSÃO}

\section{Desempenho do sistema piloto para o pH}

A Tabela 3 apresenta dados referentes à significância do teste de normalidade ( $>5 \%)$ para o pH (Estágios 1 e 2), em todas as etapas propostas pelo sistema de FiME, compreendidas desde a água bruta $(A B)$, passando pelos PFRC e
FFCA até o FFCD.

Os valores de máximos e mínimos para o pH permaneceram em concordância com as recomendações do MS (BRASIL, 2021), inclusive no que diz respeito à água bruta, que apresentou valores mínimos de 7,20 e 6,00, e máximos de 7,90 e 8,30, para os Estágios 1 e 2, respectivamente.

Tabela 3: Resultado dos dados de significância para pH - Estágio 1 e 2

\begin{tabular}{ccccc}
\hline Pontos de coleta & AB1 & PFRC1 & FFCA1 & FFCD1 \\
Significância do teste de normalidade $(>5 \%)$ & $0,026^{\mathrm{E}}$ & $0,028^{\mathrm{E}}$ & $0,085^{\mathrm{N}}$ & $0,263^{\mathrm{N}}$ \\
\hline Pontos de coleta & AB2 & PFRC2 & FFCA2 & FFCD2 \\
Significância do teste de normalidade $(>5 \%)$ & $0,535^{\mathrm{N}}$ & $0,610^{\mathrm{N}}$ & $0,499^{\mathrm{N}}$ & $0,326^{\mathrm{N}}$ \\
\hline
\end{tabular}

Legenda: $\mathrm{E}$ - existe diferença significativa; $\mathrm{N}$ - não existe diferença significativa.

Fonte: Autores (2021).

Ainda assim, mesmo estando o $\mathrm{pH}$ da água bruta em concordância ao padrão de potabilidade, os resultados expuseram a atuação dos filtros quanto à alteração do referido parâmetro. Tal afirmativa apoia-se na observação dos resultados apresentados pelas estatísticas descritivas, onde foi possível constatar que a água bruta, tanto $A B 1$ quanto $\mathrm{AB} 2$, apresentou o maior valor de $\mathrm{pH}$ dentre todas as amostras analisadas, sofrendo redução ao passar pelo PFRC. Contudo, os FFCA e FFCD promoveram pouca variação do $\mathrm{pH}$, como pode ser observado nas Figuras 2 e 3 , respectivamente, para os Estágios 1 e 2 .

Nesse sentido, mesmo com a maior parte das amostras efluentes aos filtros apresentando valores entre 7,19 e 7,70, para o Estágio 1, bem como 6,45 e 7,24 no Estágio 2, as Figuras 2 e 3 ilustraram a atuação das unidades de filtração, haja vista que as leituras de $\mathrm{pH}$ para a água efluente de cada unidade de filtração apresentaram tendência para a redução do parâmetro. Possivelmente, pode ter ocorrido algum processo microbiano (formação da camada schumtzdecke) na presença da alcalinidade do meio, para apresentar essa tendência de redução do $\mathrm{pH}$

Além disso, comparando estatisticamente os valores de $\mathrm{pH}$ entre amostras de água bruta e efluentes a cada unidade de filtração, assim como as amostras efluentes a cada filtro entre si, foram encontradas diferenças significativas, como exposto na Tabela 4.

Os resultados contidos na Tabela 4 explicitaram, além de diferenças significativas entre os valores das leituras de água bruta e de todos os filtros, diferenças entre as leituras do PFRC e FFCA, sempre respeitando os referidos Estágios, mas não demonstraram diferenças significativas entre as leituras do FFCA1 e FFCD1, tampouco entre as amostras dos FFCA2 e FFCD2. Nesse sentido, as análises estatísticas evidenciaram a tendência de redução do $\mathrm{pH}$ da água filtrada em relação à água afluente, estabelecendo concordância aos resultados apresentados por Babaei et al. (2019) e Pfannes et al. (2015). Essa tendência de redução do pH pode estar associada ao início da formação da camada microbiológica, constituída por algum tipo de microrganismos consumidor de alcalinidade no meio filtrante. 
Figura 2: Variação do pH - Estágio 1

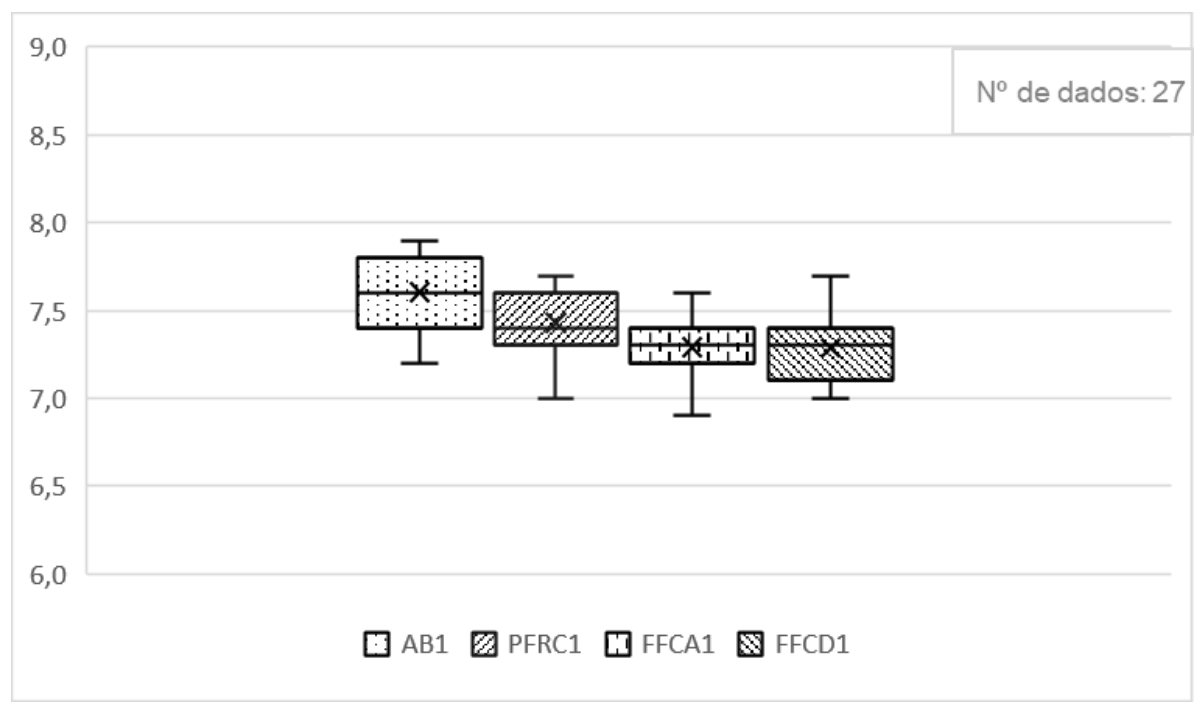

Fonte: Autores (2021).

Figura 3: Variação do pH - Estágio 2

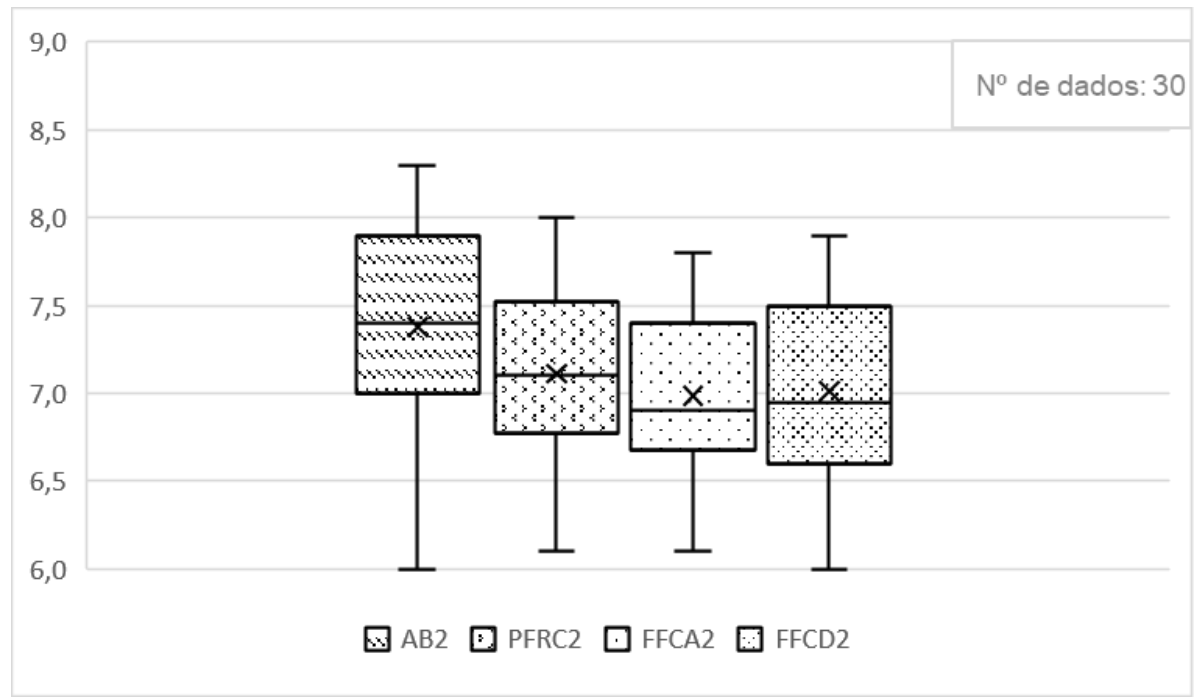

Fonte: Autores (2021).

Tabela 4: Comparação estatística entre leituras de pH ( $p$ - Valor) - Estágio 1 e 2

\begin{tabular}{|c|c|c|c|c|c|c|c|c|c|}
\hline & AB1 & PFRC1 & FFCA1 & FFCD1 & & AB2 & PFRC2 & FFCA2 & FFCD2 \\
\hline AB1 & - & $0,000^{w}$ & $0,000 \mathrm{w}$ & $0,000^{w}$ & AB2 & - & $0,000^{\top}$ & $0,000^{\top}$ & $0,000^{\top}$ \\
\hline PFRC1 & $0,000 w$ & - & $0,000 \mathrm{w}$ & $0,001 w$ & PFRC2 & $0,000^{\top}$ & - & $0,000^{\top}$ & $0,007^{\top}$ \\
\hline FFCA1 & $0,000 \mathrm{w}$ & $0,000 \mathrm{w}$ & - & $0,758^{\top}$ & FFCA2 & $0,000^{\top}$ & $0,000^{\top}$ & - & $0,199^{\top}$ \\
\hline FFCD1 & $0,000 \mathrm{w}$ & $0,001^{w}$ & $0,758^{\top}$ & - & FFCD2 & $0,000^{\top}$ & $0,007^{\top}$ & $0,199^{\top}$ & - \\
\hline
\end{tabular}

Legenda: w Teste não paramétrico de Wilcoxon. ${ }^{\top}$ Teste paramétrico "T" pareado.

Fonte: Autores (2021). 


\section{Desempenho do sistema piloto para a Temperatura}

A Tabela 5 expõe dados de significância para a temperatura, referente às observações de temperatura nos Estágios 1 e 2, nas fases propostas pelo sistema de FiME. Através destas é possível visualizar, dentre outros parâmetros, a faixa de variação da temperatura e as médias alcançadas, além da significância do teste de atendimento à distribuição normal ( $>5 \%)$.

Nesse sentido, segundo as análises estatísticas, a água bruta dos dois Estágios apresentou variação entre $24,50{ }^{\circ} \mathrm{C}$ e $29,80^{\circ} \mathrm{C}$, tendo cerca de $55 \%$ das leituras compreendidas entre $26,63^{\circ} \mathrm{C}$ e $27,68^{\circ} \mathrm{C}$ no Estágio 1 , enquanto no Estágio 2 aproximadamente $46 \%$ estiveram compreendidas entre $26,39{ }^{\circ} \mathrm{C}$ e $27,82{ }^{\circ} \mathrm{C}$. Ademais, as médias alcançadas pelos filtros apresentaram pouca variação, como pode ser observado nas Figuras 4 e 5 (Estágio 1 e 2, respectivamente), que representam a variação do referido parâmetro ao longo do período de operação do sistema.

As Figuras 4 e 5 , além de ratificarem as informações expressas na Tabela 5, apresentaram variação sutil entre as leituras de temperatura. Nesse sentido, a Figura 4 evidenciou semelhanças entre todas as fases do sistema de FiME para o Estágio 1, onde os outliers apresentados correspondem aos valores de mínimo e máximo do referido parâmetro, desde a $A B 1$ até o FFCD1. Entretanto, particularidades foram apontadas para o FFCD1 em relação às demais etapas do sistema, visto que este apresentou outlier, correspondente à temperatura de $25,30{ }^{\circ} \mathrm{C}$. Para tanto, cabe avaliar os resultados apresentados pela Tabela 6 , que traz comparações entre as etapas do sistema por meio de análises estatísticas entre as médias de temperatura através do teste de Wilcoxon, seja para o Estágio 1 como para o estágio 2.

Tabela 5: Teste de normalidade para temperatura $\left({ }^{\circ} \mathrm{C}\right)$ - Estágio 1 e 2

\begin{tabular}{ccccc}
\hline Pontos de coleta & AB1 & PFRC1 & FFCA1 & FFCD1 \\
Significância do teste de normalidade $(>5 \%)$ & $0,010^{\mathrm{E}}$ & $0,046^{\mathrm{E}}$ & $0,004^{\mathrm{E}}$ & $0,002^{\mathrm{E}}$ \\
\hline Pontos de coleta & AB2 & PFRC2 & FFCA2 & FFCD2 \\
Significância do teste de normalidade $(>5 \%)$ & $0,974^{\mathrm{N}}$ & $0,860^{\mathrm{N}}$ & $0,999^{\mathrm{N}}$ & $0,726^{\mathrm{N}}$ \\
\hline
\end{tabular}

Legenda: $\mathrm{E}$ - existe diferença significativa; $\mathrm{N}$ - não existe diferença significativa. Fonte: Autores (2021).

Figura 4: Variação da temperatura $\left({ }^{\circ} \mathrm{C}\right)$ - Estágio 1

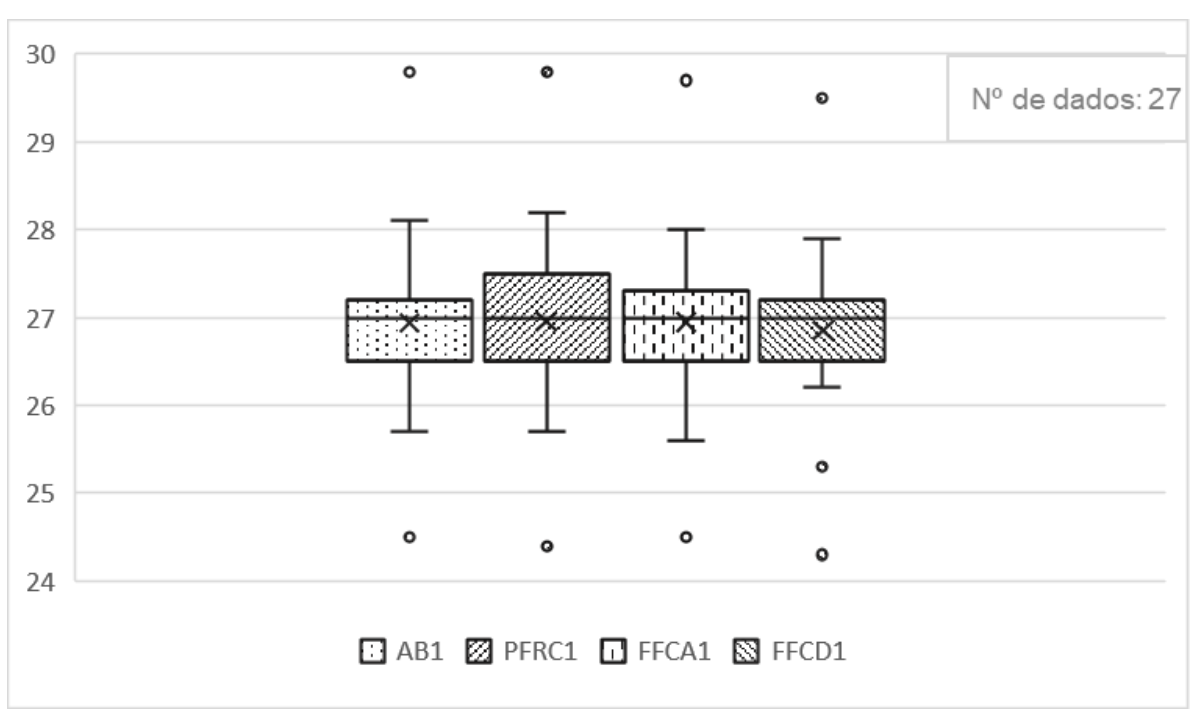

Legenda: pontos discrepantes da amostragem denominados outliers.

Fonte: Autores (2021). 
Figura 5: Variação da temperatura $\left({ }^{\circ} \mathrm{C}\right)$ - Estágio 2

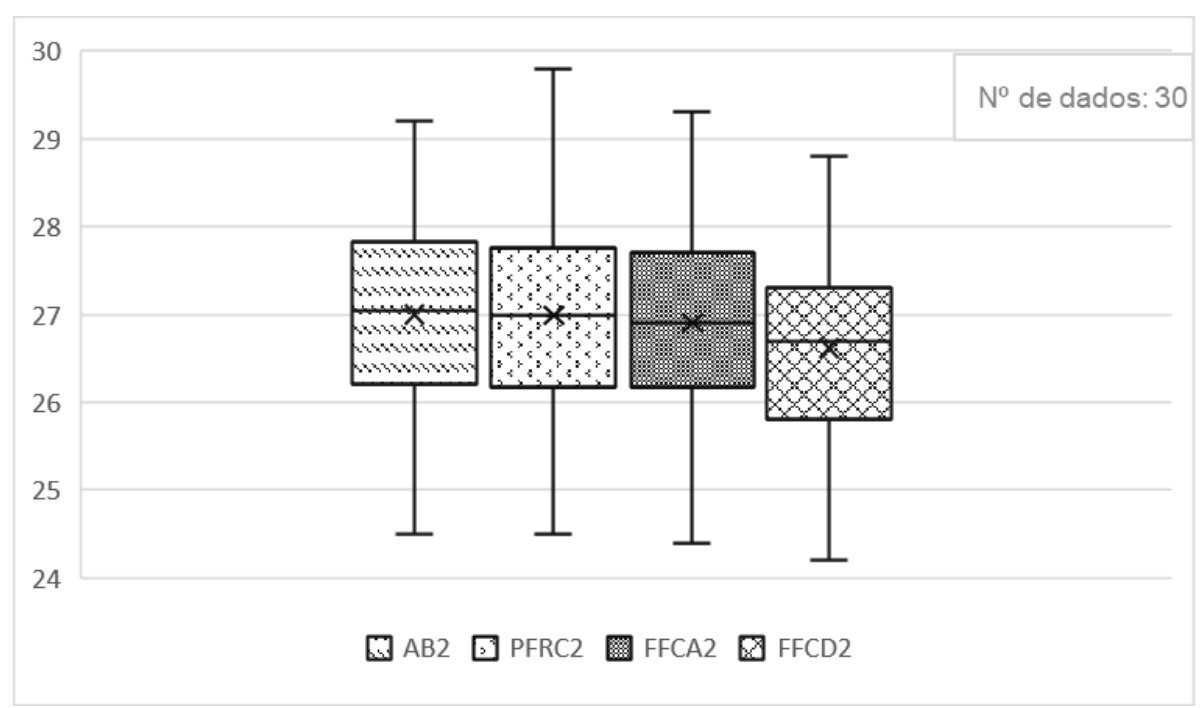

Fonte: Autores (2021).

Tabela 6: Comparação estatística entre médias de temperatura - Estágio 1 e 2

\begin{tabular}{ccccc|ccccc}
\hline & AB1 & PFRC1 & FFCA1 & FFCD1 & & AB2 & PFRC2 & FFCA2 & FFCD2 \\
\cline { 2 - 4 } \cline { 7 - 9 } AB1 & - & $0,498^{w}$ & $0,858^{w}$ & $0,015^{w}$ & AB2 & - & $0,868^{\top}$ & $0,007^{\top}$ & $0,000^{\top}$ \\
PFRC1 & $0,498^{w}$ & - & $0,599^{w}$ & $0,001^{w}$ & PFRC2 & $0,868^{\top}$ & - & $0,005^{\top}$ & $0,000^{\top}$ \\
FFCA1 & $0,858^{w}$ & $0,599^{w}$ & - & $0,001^{w}$ & FFCA2 & $0,007^{\top}$ & $0,005^{\top}$ & - & $0,000^{\top}$ \\
FFCD1 & $0,015^{w}$ & $0,001^{w}$ & $0,001^{w}$ & - & FFCD2 & $0,000^{\top}$ & $0,000^{\top}$ & $0,000^{\top}$ & - \\
\hline
\end{tabular}

Legenda: w Teste não paramétrico de Wilcoxon; ' Teste paramétrico "T" pareado.

Fonte: Autores (2021).

A Tabela 6 evidenciou ausência de diferenças significativas entre as médias das etapas $A B 1$, PFRC1 e FFCA1, entretanto, foram expressas diferenças significativas acerca da média do FFCD1 em relação as médias das demais etapas. Por outro lado, embora a Figura 5 não tenha apresentado outliers para as amostras de temperatura no Estágio 2, a comparação estatística entre médias, exposta na Tabela 6, evidenciou diferenças significativas para as médias dos FFCA2 e FFCD2 quando comparados entre si e com as demais etapas do sistema. Para tanto, foi utilizado o teste " $T$ " pareado, comparando as médias da $A B 2$ com as médias das unidades de filtração, bem como comparadas as médias do PFRC2, FFCA2 e FFCD2 entre si.

Embora diferenças significativas entre as médias de temperatura para algumas etapas dos Estágios 1 e 2 tenham sido apontadas, a variação média do parâmetro entre os referidos filtros foi de baixa amplitude, ficando em torno de $5{ }^{\circ} \mathrm{C}$, com médias em torno de $27{ }^{\circ} \mathrm{C}$. As médias apresentadas são características da região nordeste onde foi realizado o experimento.

Nesse sentido, quando os filtros lentos são submetidos a grandes variações de temperatura, a comunidade biológica pode ser significativamente afetada, entretanto, os resultados apresentados evidenciaram pouca capacidade de influência do referido parâmetro sobre o proveito do tratamento. Tal afirmativa pôde ser assegurada pela literatura, através de trabalhos como o desenvolvido por Zhang et al. (2018), que apontou a temperatura em torno de $26^{\circ} \mathrm{C}$ como ideal para o seu sistema com utilização de filtros lentos, ou ainda pelas constatações levantadas por Arnold et al. (2016), os quais defendem que os microrganismos são capazes de se adaptar a variações de temperatura, desde que estas não sejam extremas.

\section{Desempenho do sistema piloto para a Cor aparente}

A Tabela 7 (para os Estágios 1 e 2, respectivamente) apresenta dados relacionados à 
estatística (significância) para as observações de cor aparente, bem como dados sobre o IAPP e o IDQA, para cada etapa dos Estágios 1 e 2. Paralelamente, a fim de analisar o parâmetro de entrada e saída no sistema de filtração, a Tabela 8 expõe os IAPP e IDQA globais, considerando, portanto, apenas os valores para a água bruta ( $A B 1$ e $A B 2)$ e água filtrada ( $A F 1$ e AF2) efluente ao sistema de FiME.

Tabela 7: Nível de significância dos dados, IAPP e IDQA referente à cor aparente para cada etapa do sistema (UC) - Estágio 1 e 2

\begin{tabular}{ccccc}
\hline & AB1 & PFRC1 & FFCA1 & FFCD1 \\
Significância do teste de normalidade $(>5 \%)$ & $0,317^{\mathrm{N}}$ & $0,210^{\mathrm{N}}$ & $0,424^{\mathrm{N}}$ & $0,007^{\mathrm{E}}$ \\
IAPP (\%) & 0,00 & 29,63 & 11,11 & 3,70 \\
IDQA (\%) & - & 0,00 & 59,26 & 55,56 \\
\hline & AB2 & PFRC2 & FFCA2 & FFCD2 \\
Significância do teste de normalidade $(>$ 5\%) & $0,012^{\mathrm{E}}$ & $0,924^{\mathrm{N}}$ & $0,048^{\mathrm{E}}$ & $0,003^{\mathrm{E}}$ \\
IAPP (\%) & 0,00 & 6,67 & 13,33 & 13,33 \\
IDQA (\%) & - & 0,00 & 33,33 & 43,33 \\
\hline
\end{tabular}

Legenda: $\mathrm{E}$ - existe diferença significativa; $\mathrm{N}$ - não existe diferença significativa.

Fonte: Autores (2021).

Tabela 8: IAPP e IDQA do sistema para cor aparente - Estágios 1 e 2

\begin{tabular}{ccccc}
\hline & AB1 & AF1 & AB2 & AF2 \\
IAPP (\%) & 0,00 & 3,70 & 0,00 & 13,33 \\
IDQA (\%) & - & 22,22 & - & 13,33 \\
\hline
\end{tabular}

Fonte: Autores (2021).

Os valores de cor aparente apresentados para a água bruta de cada Estágio apresentaram semelhanças em suas ordens de grandeza, a exemplo de suas médias, que permaneceram na ordem de 70 uC. Além disso, os valores de mínimo para $A B 1$ e $A B 2$ foram $23 \mathrm{uC}$ e $27 \mathrm{uC}$, respectivamente, ambos acima do VMP estabelecido pelo MS, ratificando os valores descritos para seus respectivos IAPP.

Quanto às análises de cor parente, as Figuras 6 e 7 esboçam o comportamento temporal das etapas de filtração em relação à água bruta para os Estágios 1 e 2, respectivamente.

Figura 6: Comportamento temporal de cor aparente - Estágio 1

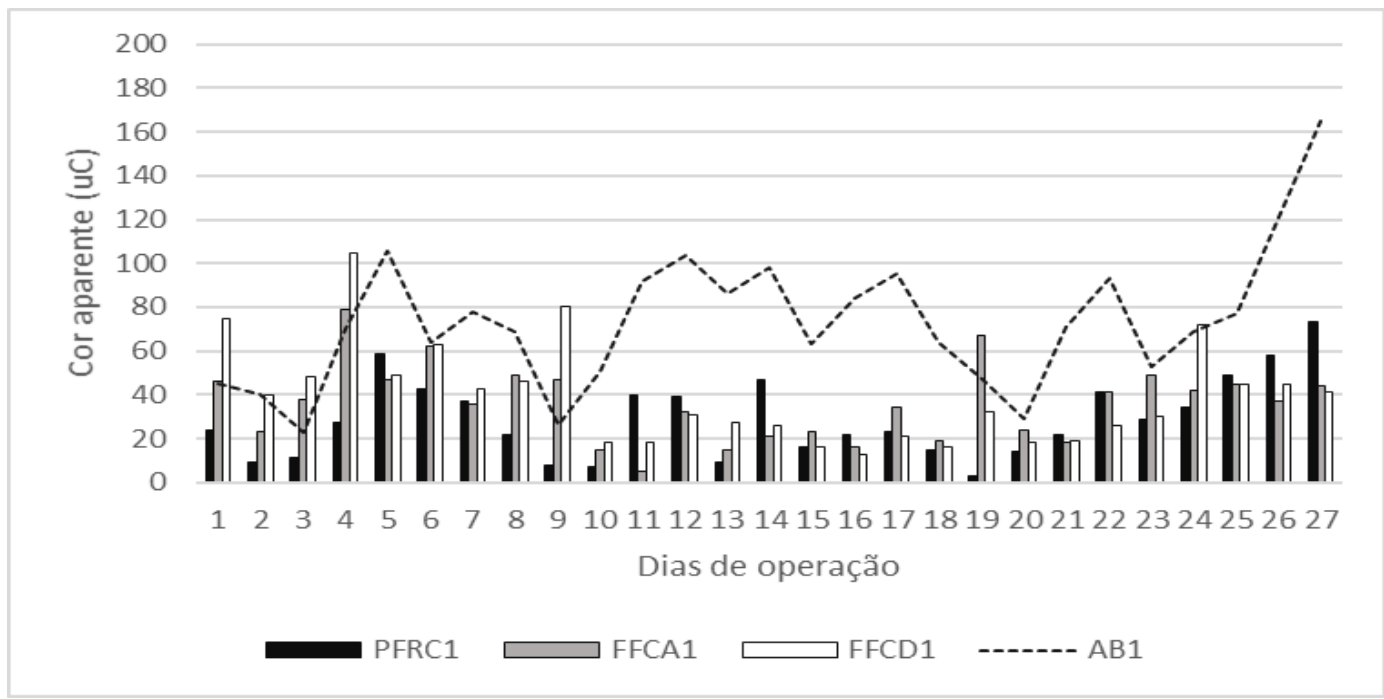

Fonte: Autores (2021). 
Figura 7: Comportamento temporal de cor aparente - Estágio 2

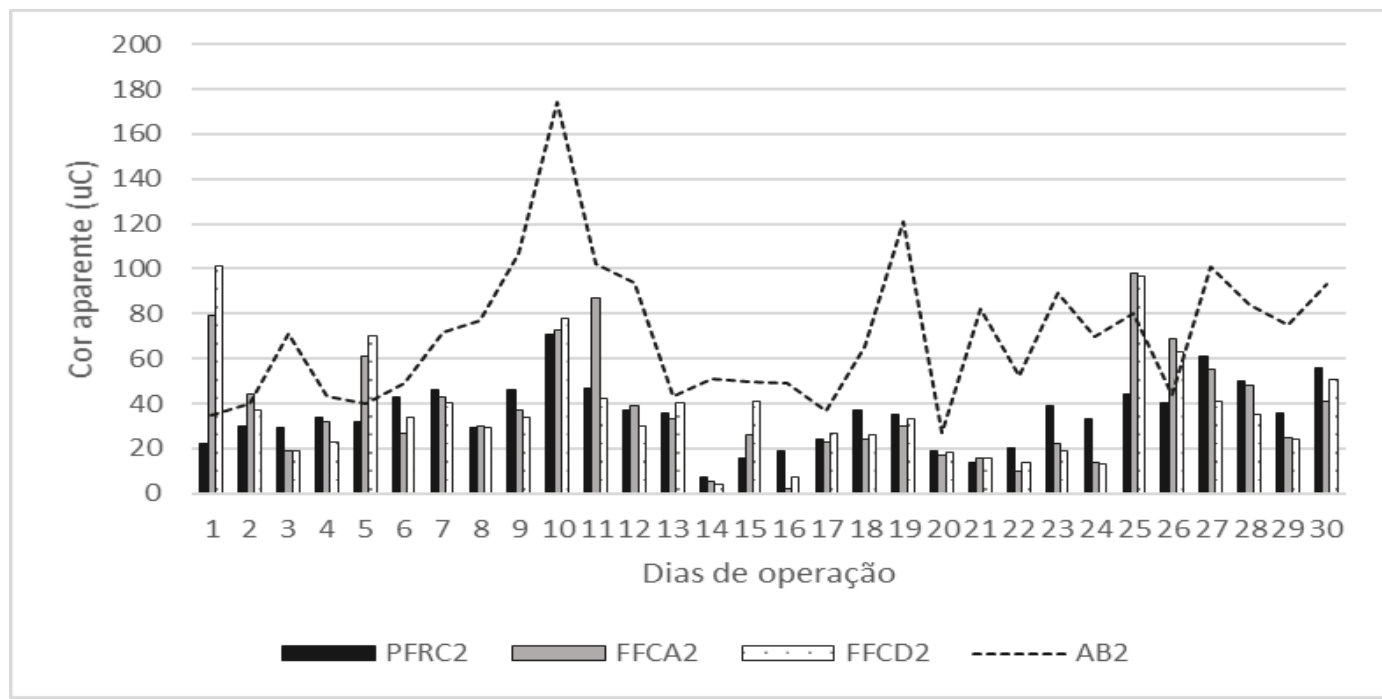

Fonte: Autores (2021).

Embora as unidades de filtração não tenham atingido significativos IAPP, os resultados de monitoramento da cor aparente mostraram que houve melhoria na qualidade da água filtrada em relação a água bruta, corroborando os valores de IAPP e IDQA expressos na Tabela 8. Entretanto, o monitoramento de desempenho dos filtros apresentou alguns picos de piora da qualidade da água, expondo valores que superaram os valores referentes à água bruta.

O monitoramento mostrou ainda que a redução de cor aparente ocorreu de forma mais acentuada nos PFRC1 e PFRC2 em comparação às demais etapas de filtração, respeitando seus respectivos Estágios. O comportamento dos
PFRC1 e PFRC2 ratificam às análises de significância expostas na Tabela 7, que expuseram ausência de piora da qualidade da água afluente, expressa pelo IDQA igual a zero para esses filtros.

Por outro lado, as análises de IDQA dos FFCA1, FFCD1, FFCA2 e FFCD2 evidenciaram queda na qualidade da água, sobretudo nos dois primeiros, que apresentaram IDQA de 59,26\% e $55,56 \%$, respectivamente. Tal verificação pôde ser amparada pelos resultados de testes estatísticos apresentados na Tabela 9 (respectivamente para os Estágios 1 e 2), quando foram comparadas as médias de cor aparente da água bruta e efluente a cada unidade de filtração, bem como as amostras efluentes de cada unidade entre si.

Tabela 9: Comparação estatística entre médias de cor aparente - Estágio 1 e 2

\begin{tabular}{|c|c|c|c|c|c|c|c|c|c|}
\hline & AB1 & PFRC1 & FFCA1 & FFCD1 & & AB2 & PFRC2 & FFCA2 & FFCD2 \\
\hline AB1 & - & $0,000^{\top}$ & $0,000^{\top}$ & $0,001^{w}$ & AB2 & - & $0,000 \mathrm{w}$ & $0,000 \mathrm{w}$ & $0,000 \mathrm{w}$ \\
\hline PFRC1 & $0,000^{\top}$ & - & $0,118^{\top}$ & $0,148 w$ & PFRC2 & $0,000 \mathrm{w}$ & - & $0,446^{w}$ & $0,325^{w}$ \\
\hline FFCA1 & $0,000^{\top}$ & $0,118^{\top}$ & - & $0,328 w$ & FFCA2 & 0,000 w & 0,446 w & - & $0,927^{w}$ \\
\hline FFCD1 & $0,001^{w}$ & $0,148 \mathrm{w}$ & $0,328 w$ & - & FFCD2 & $0,000 \mathrm{w}$ & $0,325^{w}$ & $0,927 w$ & - \\
\hline
\end{tabular}

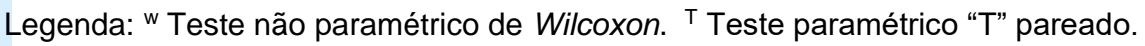

Fonte: Autores (2021).

As análises estatísticas puderam expressar a existência de diferenças significativas entre as médias de água bruta e as médias referentes às unidades de filtração para os dois Estágios, mas não foram encontradas diferenças significativas entre as médias das unidades de filtração entre si. Nesse sentido, os PFRC1 e PFRC2 apresentaram médias com diferenças significativas quando comparados à água bruta, mas não quando comparados às demais etapas de filtração dos respectivos Estágios.

Entretanto, o exposto não contradiz o desempenho dos PFRC1 e PFRC2, tampouco infere que o desempenho dos FFCA e FFCD dos 
Estágios 1 e 2 tenha sido tão efetivo quanto os PFRC1 e PFRC2, pelo contrário. A ausência de diferenças significativas entre as médias supracitadas indica que os FFCA1, FFCD1, FFCA2 e FFCD2 não foram capazes de promover melhorias na água efluente aos PFRC1 e PFRC2, respectivamente.

Nesse sentido, as análises estatísticas em conjunto aos IAPP e IDQA, respeitando os respectivos Estágios, evidenciaram o notório desempenho dos PFRC1 e PFRC2. Além disso, ratificando o exposto, as Figuras 8 e 9 ilustram o desempenho de cada etapa de filtração frente à remoção de cor aparente, bem como a eficiência global do sistema de FiME, para os Estágios 1 e 2, respectivamente.

Figura 8: Eficiência de remoção de cor aparente - Estágio 1

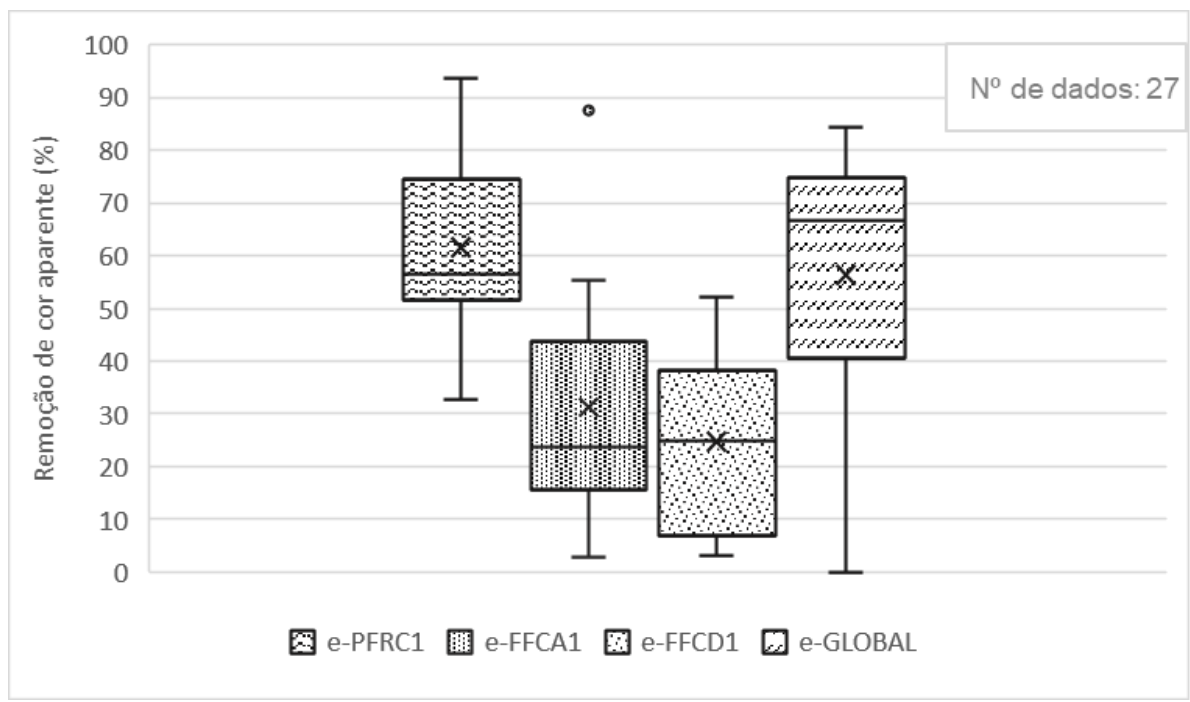

Legenda: pontos discrepantes da amostragem denominados outliers. Fonte: Autores (2021).

Figura 9: Eficiência de remoção de cor aparente - Estágio 2

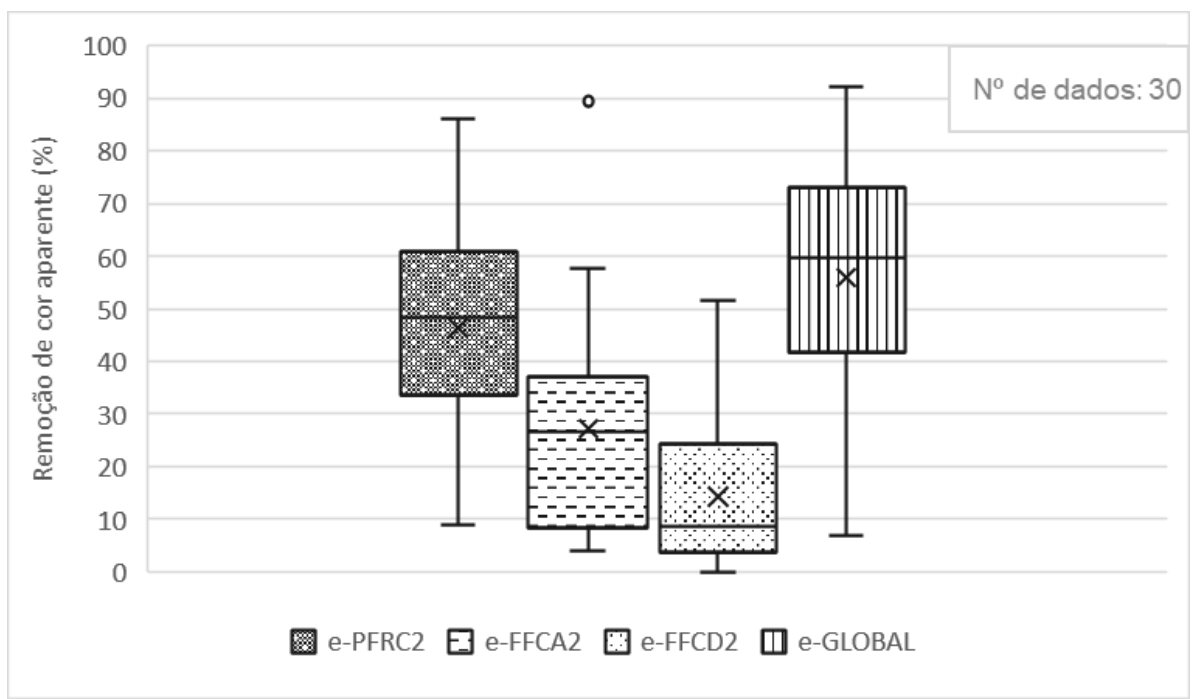

Legenda: pontos discrepantes da amostragem denominados outliers.

Fonte: Autores (2021).

Tendo em vista que houve variação entre as médias de $A B 1$ e $A B 2$, foram realizadas análises estatísticas pelo teste Mann-Whitney sobre as amostras das etapas do sistema de FiME, a fim de 
que se tornasse possível estabelecer comparações entre as eficiências médias de remoção de cor aparente para as etapas de filtração dos dois Estágios. No entanto, os resultados alcançados não apresentaram diferenças significativas entre as amostras das etapas de filtração do Estágio 1 em relação ao Estágio 2, tampouco sobre $A B 1$ e $A B 2$, evidenciando que os dois Estágios foram alimentados com águas estatisticamente iguais.

Concernente às eficiências globais do sistema, os Estágios 1 e 2 apresentaram médias de remoção de cor aparente em torno de $56 \%$ e, de modo geral, apresentaram-se em concordância às análises apresentadas anteriormente. Entretanto, conforme as Figuras 8 e 9, as eficiências médias de remoção de cor aparente para os PFRC2, FFCA2 e FFCD2 apresentaram redução em relação às eficiências médias alcançadas pelos PFRC1, FFCA1 e FFCD1, respectivamente.

Nesse sentido, análises estatísticas pelo teste Mann-Whitney também foram realizadas sobre as eficiências de remoção de cor aparente dos dois Estágios. Os resultados apresentaram diferenças significativas entre as eficiências médias dos PFRC1 e PFRC2, ratificando o exposto nas Figuras 8 e 9, que apresentaram as eficiências médias de aproximadamente $60 \%$ para o PFRC1 e $46 \%$ para o PFRC2. Contudo, a diferença entre as médias das eficiências supracitadas pode estar associada a um possível processo de colmatação dos poros da cerâmica, muito embora não tenha sido identificada perda de carga associada.

Diferenças significativas quanto à comparação entre as eficiências médias de remoção dos FFCA1 e FFCA2, bem como entre as eficiências médias de remoção dos FFCD1 e FFCD2, não foram identificadas. Para tanto, uma vez que a água de estudo utilizada nos dois Estágios foi estatisticamente igual, e diante da comparação estatística entre as eficiências dos FFCA1, FFCD1, FFCA2 e FFCD2, infere-se que a adição de três camadas de manta não tecida sobre o leito filtrante de fibra de coco foi insuficiente para promover melhorias frente à eficiência na remoção de cor aparente.

Por outro lado, cabe ressaltar que a adição das camadas de manta foi conveniente para promover maior estabilidade dos FFCA2 e FFCD2, visto que, uma vez avaliados seus respectivos IAPP e IDQA, esses filtros foram capazes de alcançar maiores níveis de atendimento ao padrão de potabilidade e apresentaram menores valores de IDQA, quando comparados aos FFCA1 e FFCD1. Todavia, estudos realizados por Santos (2015) evidenciaram que o bom desempenho dos filtros com leito filtrante de manta não tecida, frente à remoção de parâmetros físicos, ocorre predominantemente em função do amadurecimento biológico do meio filtrante.

Dessa forma, tendo em vista os processos utilizados pelos filtros lentos para melhoria da qualidade da água filtrada, Zhang et al. (2018) expressam que o sistema só é efetivamente inicializado a partir do alcance de uma faixa de remoção estável e, indo além, Verma et al. (2017) apontam que a operação estável dos filtros lentos é alcançada após formação da camada biologicamente ativa.

Possivelmente, o período de operação dos filtros nos Estágios 1 e 2 pode não ter sido suficiente para favorecer a formação completa da schmutzdecke, visto que são necessários, em média, 30 dias de operação para alcançar os primeiros resultados, como indica CAWST (2012), em conformidade com Zhang et al. (2018), que observaram a formação do biofilme a partir de 33 dias de operação do seu sistema.

Nesse contexto, considerando a não formação da schmutzdecke, o processo filtração seguido de adsorção foi predominante para a melhoria na qualidade da água filtrada, entretanto Verma et al. (2017) defendem que sua atuação é diretamente afetada quando há redução de profundidade do leito filtrante. Ademais, o desempenho inferior dos FFCA1, FFCD1, FFCA2 e FFCD2, quando comparados aos PFRC1 e PFRC2, pode estar associado à reduzida profundidade dos seus respectivos leitos filtrantes, cerca de $16 \mathrm{~cm}$ para os leitos de fibras contra 38 $\mathrm{cm}$ para o PFRC.

Além disso, outra interferência pode estar associada ao possível desprendimento de sólidos dissolvidos, responsáveis pela agregação da cor por parte das fibras utilizadas como meio filtrante, e posterior incremento de cor na água de estudo. Situação semelhante foi enfrentada por Lima (2020), ao utilizar resíduo de maravalha de angelim-vermelho como camada intermediária em seus filtros lentos. Todavia, as possíveis dificuldades enfrentadas pelos filtros com fibra de coco podem ser potencialmente evitadas e/ou corrigidas através de adequações aos filtros, como aumento de profundidade dos leitos filtrantes e mudanças no pré-tratamento utilizado para as 
fibras, como permanência em água destilada por mais tempo ou mesmo através da aplicação de pré-tratamentos mais rigorosos, como tratamentos químicos.

Ainda vale ressaltar que, de modo geral, o pré-filtro no sistema de filtração em múltiplas etapas não é projetado com a finalidade de promover a qualidade final da água tratada. Entretanto os PFRC1 e PFRC2 apresentaram comportamento promissor frente aos elevados valores de cor aparente encontrados na água bruta, oferecendo estabilidade durante todo $\mathrm{O}$ período de operação, visto que o IDQA apresentado foi igual a zero para os dois Estágios. Ao se comparar os resultados dos pré-filtros, quanto à remoção de cor, com os obtidos por Nascimento, Pelegrini e Brito (2012), Souza et al. (2016) e Terin (2017), para remoção de cor de $50 \%, 75 \%$ e $98 \%$, respectivamente em filtros lentos, observa-se que os pré-filtros PFRC1 e PFRC2 apresentaram bom desempenho.

Em conformidade ao exposto, Jayalath et al. (2016) e Rajapakse e Fenner (2011) também obtiveram resultados positivos com uso de materiais cerâmicos em detrimento ao uso dos tradicionais seixos nos pré-filtros.

\section{Desempenho do sistema piloto para a Turbidez}

A Tabela 10 traz dados acerca das estatísticas descritivas de turbidez para a água afluente e efluente a cada filtro, considerando os Estágios 1 e 2, respectivamente. Paralelamente, as Figuras 10 e 11 ilustram o comportamento temporal das etapas de filtração em relação à água bruta para os Estágios 1 e 2, respectivamente.

Tabela 10: Nível de significância, IAPP e IDQA dos dados de turbidez (UT) - Estágio 1 e 2

\begin{tabular}{ccccc}
\hline & AB1 & PFRC1 & FFCA1 & FFCD1 \\
\cline { 2 - 5 } Significância do teste de normalidade $(>5 \%)$ & $0,699^{\mathrm{N}}$ & $0,112^{\mathrm{N}}$ & $0,248^{\mathrm{N}}$ & $0,001^{\mathrm{E}}$ \\
IAPP (\%) & 7,14 & 25,93 & 22,22 & 25,93 \\
IDQA (\%) & - & 3,70 & 48,15 & 44,44 \\
\hline & AB2 & PFRC2 & FFCA2 & FFCD2 \\
\cline { 2 - 5 } Significância do teste de normalidade $(>5 \%)$ & $0,005^{\mathrm{E}}$ & $0,038^{\mathrm{E}}$ & $0,028^{\mathrm{E}}$ & $0,001^{\mathrm{E}}$ \\
IAPP (\%) & 3,33 & 26,67 & 23,33 & 30,00 \\
IDQA (\%) & - & 0,00 & 30,00 & 13,33 \\
\hline
\end{tabular}

Legenda: $\mathrm{E}$ - existe diferença significativa; $\mathrm{N}$ - não existe diferença significativa.

Fonte: Autores (2021).

Figura 10: Comportamento temporal de turbidez - Estágio 1

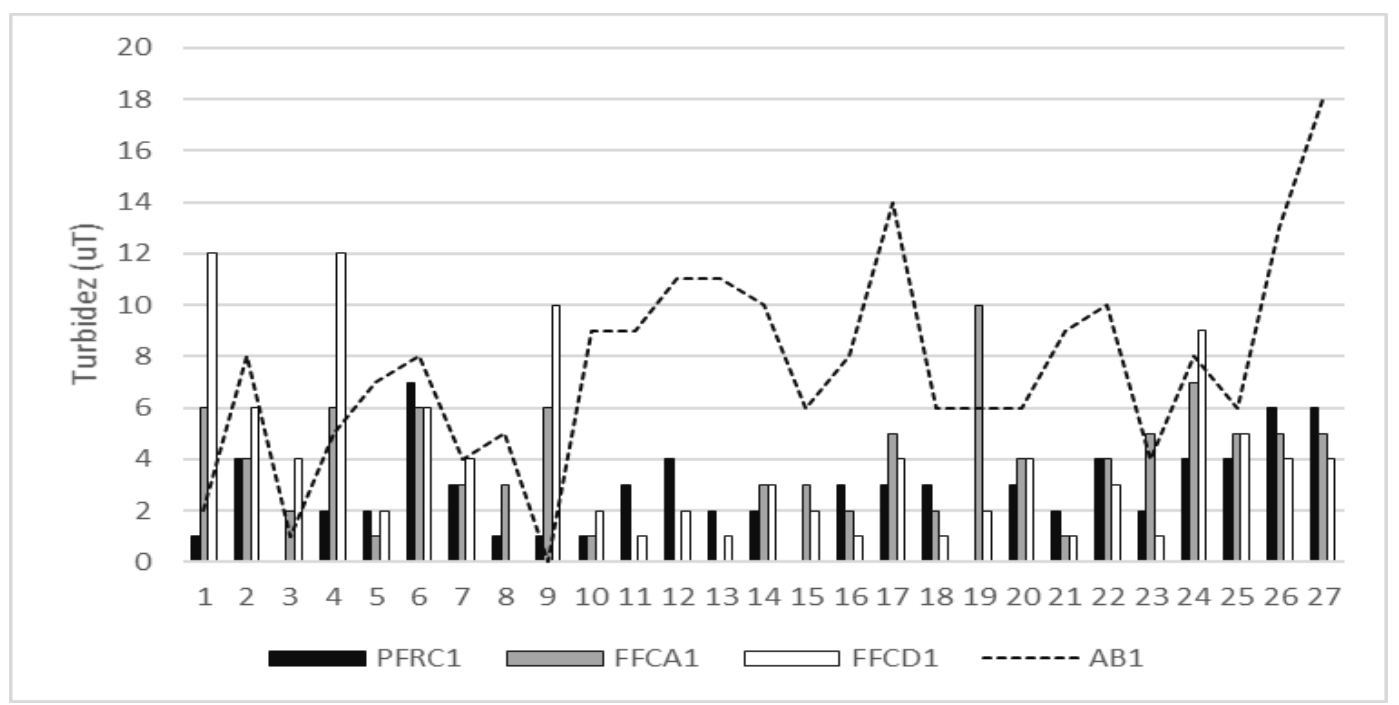

Fonte: Autores (2021). 
Figura 11: Comportamento temporal de turbidez - Estágio 2

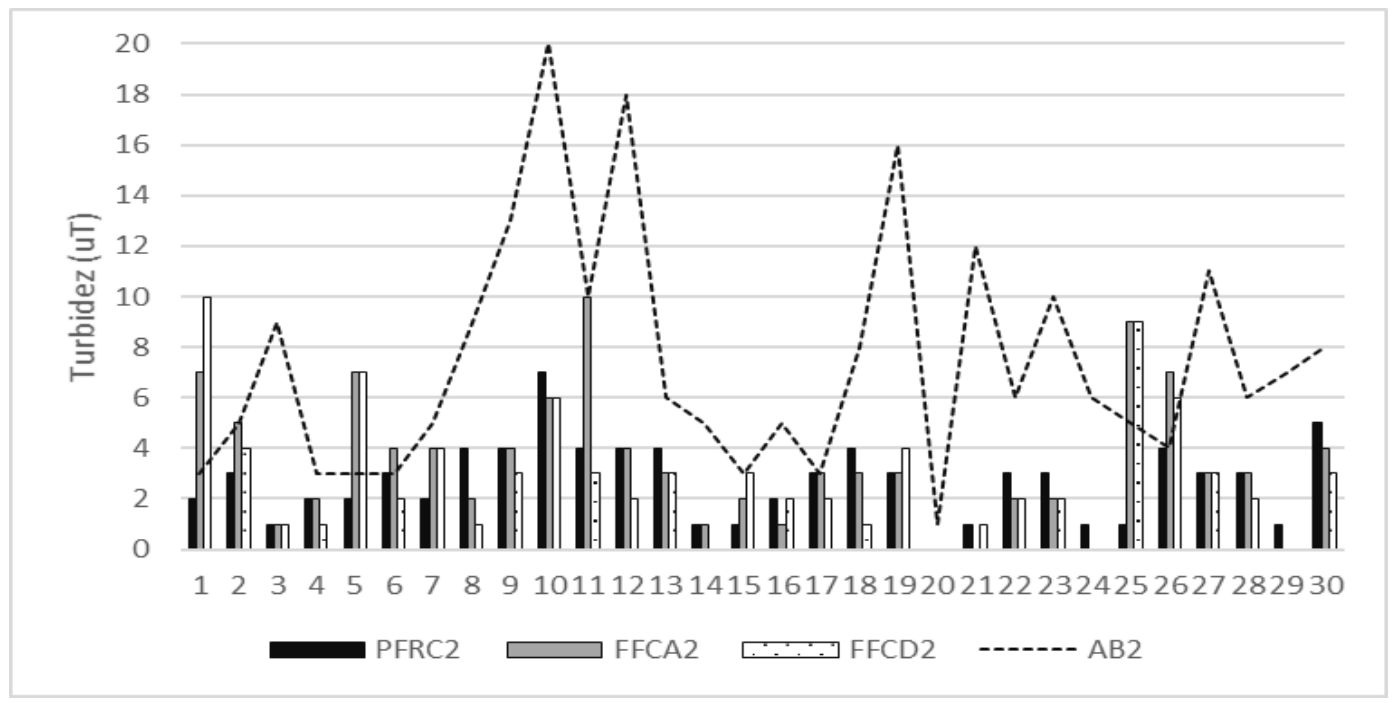

Fonte: Autores (2021).

De acordo com as análises de estatística descritiva, a turbidez da água bruta apresentou variação média de 0 a 20 uT, salientando que a maior parte das amostras, representadas por aproximadamente $40 \%$, apresentaram valores compreendidos entre 3,61 e 7,20 UT no Estágio 1, enquanto no Estágio 2 os valores ficaram entre 4,81 e 8,60 uT. Para tanto, em se tratando do IAPP para $\mathrm{AB} 1$, apenas $7,41 \%$ das amostras conseguiram apresentar turbidez menor ou igual a
1 uT, como exige padrão de potabilidade instituído pelo MS para água na saída de filtros lentos, ao passo em que situação mais desfavorecida foi encontrada para AB2, apresentando apenas $3,33 \%$ das amostras estiveram em concordância à Portaria de Potabilidade (BRASIL, 2021).

Nesse sentido, a Tabela 11 apresenta os IAPP e IDQA globais do sistema considerando apenas os valores de água bruta (AB1 e $A B 2)$ e água filtrada ( $\mathrm{AF} 1$ e AF2) de ambos os estágios.

\begin{tabular}{l} 
Tabela 11: IAPP e IDQA do sistema para turbidez - Estágios 1 e 2 \\
\cline { 2 - 5 } \\
\cline { 2 - 5 }
\end{tabular}

Fonte: Autores (2021).

Embora o IAPP alcançado pelo sistema não ultrapasse a marca de $30 \%$, o monitoramento de turbidez contido nas Figuras 10 e 11 trouxe resultados positivos sobre a melhoria na qualidade da água filtrada em relação a água bruta, constatando que houve redução de turbidez na água filtrada desde o início de operação do sistema.

Semelhantemente ao monitoramento de cor aparente, o desempenho dos filtros para a turbidez apresentou alguns picos de piora da qualidade da água filtrada, inclusive tendo algumas leituras de água filtrada com valores de turbidez acima dos valores atribuídos à água bruta. Todavia, foi observado que as leituras das amostras efluentes aos filtros que apresentaram picos de turbidez foram realizadas nos mesmos dias das leituras de água filtrada que apresentaram picos de cor aparente, permitindo inferir que os dias em que os filtros permaneceram sem operação foram capazes de influenciar negativamente não apenas os resultados de cor aparente, mas também nos resultados de turbidez.

Para mais, o IDQA dos PFRC1 e PFRC2 para turbidez apresentou resultados satisfatórios, visto que, de modo geral, foi onde ocorreu redução do parâmetro de forma mais acentuada. Tais afirmações apoiam-se ainda na Tabela 12 (Estágios 1 e 2, respectivamente), que trazem informações acerca de comparações entre as 
análises estatísticas das médias obtidas para cada etapa do sistema.

Os resultados evidenciaram diferenças significativas entre as médias dos PFRC1 e AB1, bem como PFRC2 e AB2, respectivamente, mas não evidenciaram diferenças significativas quando comparadas as médias dos PFRC, FFCA e FFCD entre si, considerando os referidos Estágios. A ausência de diferenças significativas entre as médias supracitadas indica que os FFCA1, FFCD1, FFCA2 e FFCD2 não foram capazes de promover melhorias na água efluente aos PFRC1 e PFRC2.

Nesse sentido, as Figuras 12 e 13 ilustram as eficiências de remoção para cada unidade de filtração, bem como a eficiência global do sistema, para os Estágios 1 e 2, respectivamente.

Para tanto, a fim de promover análises comparativas sobre as eficiências médias de remoção de turbidez dos Estágios 1 e 2, análises estatísticas pelo teste Mann-Whitney sobre as amostras das etapas do sistema de FiME foram realizadas. Os resultados estatísticos não apresentaram diferenças significativas entre as amostras das etapas de filtração de ambos os Estágios, tampouco sobre $A B 1$ e $A B 2$, evidenciando que os dois Estágios foram alimentados com águas estatisticamente iguais.

Em se tratando da eficiência de remoção de turbidez, os FFCA1 e FFCD1 apresentaram eficiências médias ultrapassando a marca de $30 \%$, chegando próximo aos $40 \%$ para o FFCA1, enquanto as eficiências médias dos FFCA2 e FFCD2 ficaram em torno dos $27 \%$, de sorte que todos os filtros citados conseguiram, em algumas amostras, atingir $100 \%$ de eficiência na remoção de turbidez. Por outro lado, os PFRC1 e PFRC2 atingiram eficiências médias de $64 \%$ e $57 \%$, respectivamente, ultrapassando as eficiências médias alcançadas pelos FFCA1, FFCA2, FFCD1 e FFCD2.

Tabela 12: Comparação estatística entre médias de turbidez - Estágio 1 e 2

\begin{tabular}{ccccc|ccccc}
\hline & AB1 & PFRC1 & FFCA1 & FFCD1 & & AB2 & PFRC2 & FFCA2 & FFCD2 \\
\cline { 2 - 5 } AB1 & - & $0,000^{\top}$ & $0,000^{\top}$ & $0,007^{w}$ & AB2 & - & $0,000^{w}$ & $0,001^{w}$ & $0,000^{w}$ \\
PFRC1 & $0,000^{\top}$ & - & $0,097^{\top}$ & $0,373^{w}$ & PFRC2 & $0,000^{w}$ & - & $0,319^{w}$ & $0,571^{w}$ \\
FFCA1 & $0,000^{\top}$ & $0,097^{\top}$ & - & $0,436 \mathrm{w}$ & FFCA2 & $0,001^{w}$ & $0,319 w$ & - & $0,065^{w}$ \\
FFCD1 & $0,007^{w}$ & $0,373^{w}$ & $0,436^{w}$ & - & FFCD2 & $0,000 w$ & $0,571 w$ & $0,065^{w}$ & - \\
\hline
\end{tabular}

Legenda: w Teste não paramétrico de Wilcoxon. 'T Teste paramétrico "T" pareado.

Fonte: Autores (2021).

Figura 12: Eficiência de remoção de turbidez - Estágio 1

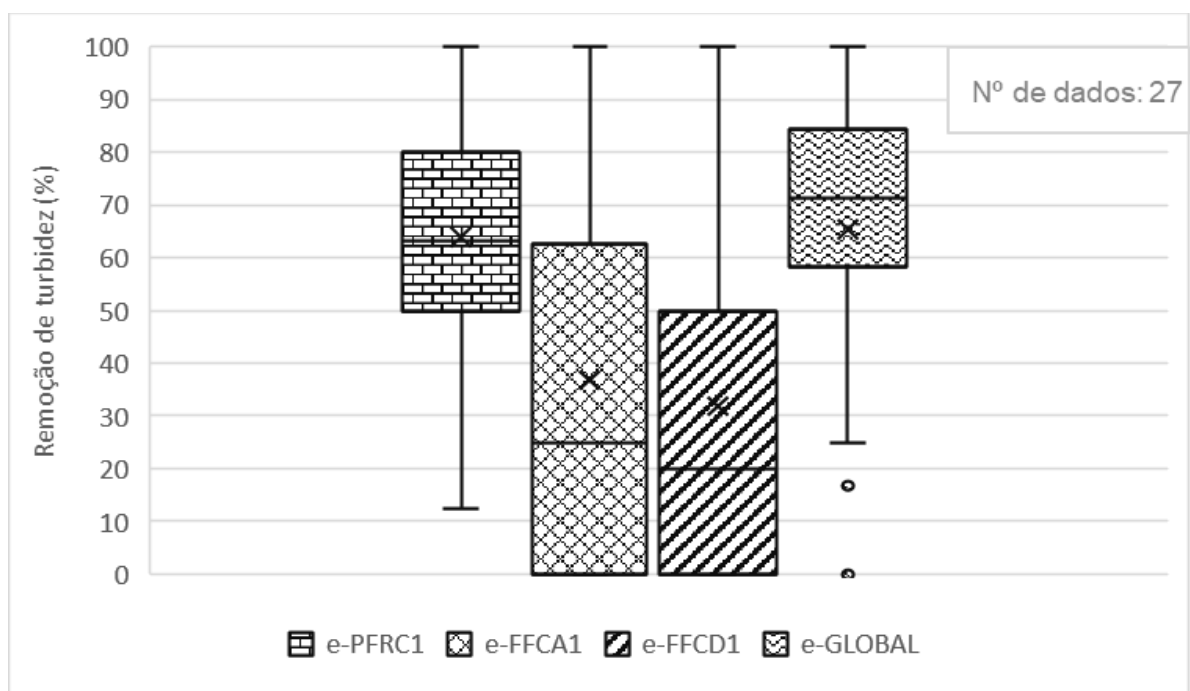

Legenda: pontos discrepantes da amostragem denominados outliers.

Fonte: Autores (2021). 
Figura 13: Eficiência de remoção de turbidez - Estágio 2

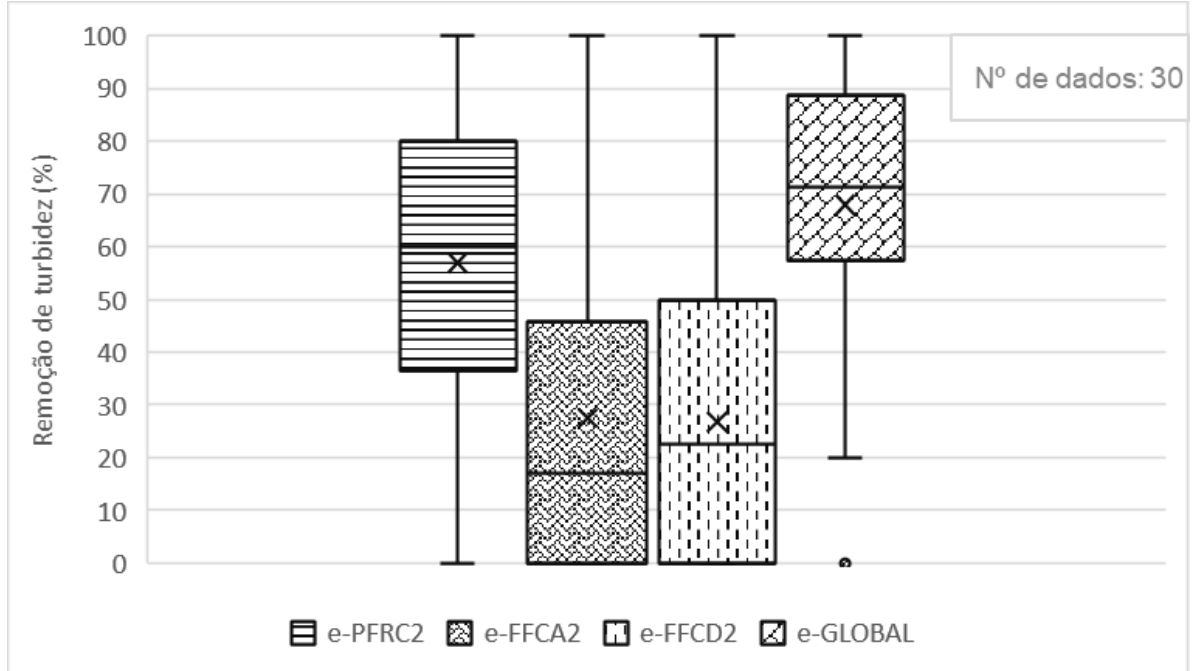

Legenda: pontos discrepantes da amostragem denominados outliers.

Fonte: Autores (2021).

Nesse sentido, foram realizadas análises estatísticas, através do teste de Mann-Whitney, a fim de comparar as eficiências médias de remoção dos FFCA1 e FFCA2, assim como as eficiências médias de remoção dos FFCD1 e FFCD2. Contudo, os resultados das análises não apresentaram diferenças significativas entre as eficiências médias dos filtros supracitados. Tendo em vista que, para fins estatísticos, os filtros dos dois Estágios foram alimentados com a mesma água de estudo e os resultados alcançados inferem que a adição das camadas de manta não foi preponderante para aumentar a eficiência na remoção de turbidez.

Tal constatação recai sobre as eficiências médias globais alcançadas pelo sistema, visto que, apesar de significativas, $65 \%$ e $68 \%$ para os Estágios 1 e 2, respectivamente, não apresentaram variações consideráveis entre si.

Por outro lado, os filtros com adição das camadas de manta (FFCA2 e FFCD2) apresentaram maior estabilidade quando comparados aos FFCA1 e FFCD1, uma vez que apresentaram melhores níveis de atendimento ao padrão de potabilidade, além da presença dos menores valores de IDQA, sobretudo no que diz respeito ao FFCD2, que apresentou maior IAPP e menor IDQA dentre todos os filtros com leito filtrante composto por fibra de coco.

Ademais, diante da ausência de diferenças significativas também para as análises estatísticas sobre as eficiências médias dos PFRC1 e PFRC2, cabe ressaltar que ambos apresentaram desempenho promissor, sobretudo por apresentarem eficiência média de remoção de turbidez em torno de $64 \%$ no primeiro e $57 \%$ para o último, estabelecendo caminhamento para os resultados de testes iniciais apresentados por Jayalath et al. (2016), que alcançaram cerca de $75 \%$ de eficiência na remoção de turbidez em seus pré-filtros de resíduo cerâmico.

Sendo assim, uma vez que os filtros analisados quanto à turbidez foram os mesmos analisados em relação à cor aparente, o curto período de operação dos filtros não favoreceu a formação da camada biológica, restando, predominantemente, a filtração seguida de adsorção, a responsabilidade pela remoção de turbidez. Além disso, os fatores associados ao desempenho inferior dos FFCA e FFCD para remoção de cor aparente também podem estar associados à remoção de turbidez.

Não obstante, $89 \%$ das amostras de $A B 1$ apresentaram valores acima de $2 \mathrm{uT}$, ao passo em que a Portaria de Potabilidade (BRASIL, 2021) tolera apenas até $5 \%$ das amostras tratadas por filtração lenta com 2 uT; o PFRC1 pôde promover redução considerável do parâmetro, diminuindo para $52 \%$ o número de amostras efluentes com valores acima de 2 uT. Contudo, apesar dos ganhos alcançados com o PFRC1, há ainda a necessidade de melhorias no sistema, visto que $67 \%$ das amostras efluentes ao FFCA1, e $57 \%$ das amostras efluentes ao FFCD1, ainda apresentaram valores de turbidez consideravelmente distantes do exigido para 0 consumo humano.

Situação mais desfavorável ocorreu com a 
$A B 2$, quando $97 \%$ das amostras atingiram valores acima de 2 uT. Por outro lado, o PFRC2 reduziu para $57 \%$ do número de amostras efluentes acima de 2 uT, enquanto o FFCA2 apresentou $60 \%$ e o FFCD2 47\%. Nesse sentido, é admissível ratificar a possível estabilidade alcançada por consequência do uso das camadas de manta não tecida, sobretudo ao observar que os percentuais de amostras acima de 2 UT nos FFCA2 e FFCD2 são menores que nos FFCA1 e FFCD1, apesar da considerável piora na qualidade da $\mathrm{AB} 2 \mathrm{em}$ relação a $A B 1$.

\section{CONCLUSÕES}

Com base nos resultados alcançados, testes estatísticos apontaram que os Estágios 1 e 2 foram alimentados com a mesma água de estudo, viabilizando comparações sobre o desempenho dos filtros atuantes nos dois Estágios.

Os resultados estatísticos evidenciaram diferenças significativas sobre as médias de $\mathrm{pH}$, temperatura, cor aparente e turbidez entre as amostras afluentes e efluentes aos filtros, respeitando seus respectivos Estágios. Entretanto não foram apresentadas diferenças significativas entre as médias dos parâmetros supracitados frente à comparação entre amostras dos Estágios 1 e 2. Ademais, as alterações promovidas pelos filtros nos parâmetros de $\mathrm{pH}$ e temperatura não exerceram forte influência sobre o desempenho do sistema, haja vista o baixo nível de variação em relação à água bruta.

De modo geral, as eficiências médias de remoção de cor aparente e turbidez alcançadas pelos filtros lentos com fibra de coco de fluxo ascendente (FFCA1) e descendente (FFCD1), do Estágio 1, não apresentaram diferenças estatísticas significativas em relação às eficiências médias apresentadas pelos filtros lentos com fibra de coco de fluxo ascendente (FFCA2) e descendente (FFCD2) do Estágio 2, respectivamente. Apesar da adição de três camadas de manta não tecida sobre o leito filtrante dos FFCA2 e FFCD2 ter se mostrado pouco efetiva frente à eficiência de remoção dos parâmetros físicos, esta se mostrou atuante quanto à promoção da estabilidade dos filtros, de forma que os FFCA2 e FFCD2 apresentaram menores IDQA que os seus equivalentes no Estágio 1.

Os pré-filtros com leito filtrante de resíduo cerâmico dos dois Estágios (PFRC1 e PFRC2) apresentaram comportamento promissor frente aos significativos valores de cor aparente encontrados na água bruta, com $60 \%$ de eficiência média de remoção para o primeiro e $46 \%$ para o segundo, além de IDQA igual a zero para ambos, oferecendo estabilidade durante todo o período de operação. Desempenho satisfatório também foi apresentado frente à eficiência na remoção de turbidez, onde o PFRC1 apresentou média de $64 \%$, ao passo que o PFRC2 apresentou $57 \%$. Destaca-se que, apesar da obtenção das remoções, a cor aparente ainda não apresentou resultado enquadrado para consumo humano.

Nesse sentido, a adição das camadas de manta não tecida proporcionou maior estabilidade aos filtros FFCA2 e FFCD2, enquanto a incorporação de resíduos de cerâmica vermelha e fibras de coco, além de agregar viés ambiental e econômico, promoveu remoção de cor aparente e turbidez baseada, sobretudo, na capacidade filtração seguida de adsorção destes materiais.

Assim, o uso de materiais não convencionais na aplicação da técnica de filtração em múltiplas etapas é bem-vindo, tanto no sentido de aproveitamento de materiais que seriam descartados, como no quesito de eficiência de tratamento de água. Porém, estudo com carreira de filtração mais longo (proposta para estudos futuros), que favoreça a formação da camada microbiana, pode proporcionar resultados mais alinhados às recomendações da Portaria de Potabilidade do Ministério da Saúde.

\section{REFERÊNCIAS}

ASSOCIAÇÃO BRASILEIRA DE NORMAS TÉCNICAS. NBR 10007: Amostragem de resíduos sólidos. Rio de Janeiro, 2004. $21 \mathrm{p}$.

ABNT. ASSOCIAÇÃO BRASILEIRA DE NORMAS TÉCNICAS. 1992. NBR 12216: Projeto de estação de tratamento de água para abastecimento público. Rio de janeiro, 1992, 18p.

ALMAGRO, A. S.; ROCHA, S. M. S. Aplicação de bioadsorvente de casca de coco verde para o tratamento de efluentes oleosos. In: XI Congresso Brasileiro de Engenharia Química em Iniciação Científica, 2015, Campinas. Anais [...]. Campinas: São Paulo, 2015. p. 1-6.

APHA. AMERICAN PUBLIC HEALTH ASSOCIATION; AMERICAN WATER WORKS ASSOCIATION; WATER ENVIRONMENT FEDERATION (APHA/AWWA/WEF). Standard Methods for the examination of Water and 
Wastewater. 22 st ed. Washington, DC: American Public Health Association, 2012.

ARNOLD, N.; ARCHER, A.; BARKDOLL, B. Bacterial adaptation and performance of household biosand water filters in differing temperatures. Water Science and Technology: Water Supply, v. 16, p. 794-801, 2016.

BABAEI, F.; EHRAMPOUSH, M. H.; ESLAMI, H.; GHANEIAN, M. T.; FALLAHZADEH, H.; TALEBI, P.; FOULADI-FARD, R.; EBRAHIMI, A. A. Removal of linear alkylbenzene sulfonate and turbidity from greywater by a hybrid multi-layer slow sand filter microfiltration ultrafiltration system. Journal of Cleaner Production, $n$. 211, p. 922-931, 2019.

BRAINER, M. S. C. P. Produção de coco: O Nordeste é destaque nacional. Escritório Técnico de Estudos Socioeconômicos do Nordeste (ETENE), n. 61, p. 25, 2018.

BRASIL, Ministério da Saúde. Portaria do Gabinete do Ministro (GM) do Ministério da Saúde (MS) n 888, de 04 de maio de 2021. Altera o Anexo XX da Portaria de Consolidação GM/MS nº 5, de 28 de setembro de 2017, para dispor sobre os procedimentos de controle e de vigilância da qualidade da água para consumo humano e seu padrão de potabilidade. Gabinete do Ministério. $29 \mathrm{p}$.

CARDOSO, M. S.; GONÇALEZ, J. C. Aproveitamento da casca do coco-verde (Cocos nucifera L.) para produção de polpa celulósica. Ciência Florestal, v. 26, n. 1, p. 321-330, 2016.

CAWST. Biosand Filter Construction Manual. Centre for Affordable Water and Sanitation Technology, p. 1122, 2012.

CHAN, S.; PULLERITS, K.; RIECHELMANN, J.; PERSSON, K. M.; RADSTRÕM, P.; PAUL, C. J. Monitoring biofilm function in new and matured full-scale slow sand filters using flow cytometric histogram image comparison (CHIC). Water Research, v. 138, p. 27-36, 2018.

CLARKE, B. A.; JONES, C. J.; ENGD, H. L. E.; MENG, J. L.; CROMPTON, C. C.; DOREA, S. B. Multi-stage filtration for developing world surface water treatment. Water Management, v. 157, p. 7, 2004.

D'ALESSIO, M.; EL-SWAIFY, G.; YONEYAMA, B.; RAY, C. A low-cost water-treatment system for potable water supplies in developing countries and after a natural disaster: ability to remove total coliforms and E. coli. Clean Technologies and Environmental Policy, v. 18, n. 3, p. 925-934, 2016.
DI BERNARDO, L.; SABOGAL PAZ, L. P. Seleção de tecnologias de tratamento de água. São Carlos: LDIBE LTDA, 2008.

DISA-DISA, P.; CULOT, M.; LOBO, J.; KALALA, I.; KAWITA, C.; EKOKO, G.; MULAJI, C. Traitement des eaux de consommation par filtration lente sur sable à plusieurs étapes. Revue des sciences de l'eau, v. 27, n. 3, p. 259-268, 2014.

GARCIA, E.; CABRAL JUNIOR, M.; QUARCIONI, V. A.; CHOTOLI, F. F. Resíduo de cerâmica vermelha (RCV): Uma alternativa como material pozolânico. Cerâmica Industrial, v. 19, n. 4, p. 31-38, 2014.

JAYALATH, C. P. G.; MIGUNTANNA, N. S.; PERERA, H. A. K. C. Burnt clay bricks as an alternative filter media for pebble matrix filters (PMF). Engineer: Journal of the Institution of Engineers, Sri Lanka, v. 49, n. 3, p. 1-9, 2016.

LIMA, A. J. Análise comparativa da eficiência de filtros lentos com meios filtrantes convencionais e não convencionais. 2020. Dissertação (Mestrado em Engenharia Civil) - Universidade Federal de Sergipe, São Cristóvão, 2020.

MACCAFERRI, G. I. Mactex H.2 geotêxtil não tecido. Gruppo Industriale Maccaferri, 2019.

MACHADO, L. S. M.; CARMO, W. G.S.; MACHADO, F. M.; SANTOS, S. M. Pigmentos indicadores da qualidade da água em instalação piloto de filtração em múltiplas etapas. In: XVII Simpósio Luso-Brasileiro de Engenharia Sanitária e Ambiental, 2016, Florianópolis. Anais [...]. Florianópolis: Santa Catarina, 2016. v. 17.

MENDONZA, A. L. C.; LUCAS-VIDAL, L.; HURTADO, E. A.; BARRIOS-MAESTRE, R.; SILVA-ACUÑA, R. Sistema de tratamiento de águas superficiales para consumo humano en la microcuenca del Río Carrizal, Ecuador. La Técnica, v. 21, 2019.

NASCIMENTO, A. P.; PELEGRINI, R. T.; BRITO, N. N. Filtração lenta para 0 tratamento de águas para pequenas comunidades rurais. REEC - Revista Eletrônica de Engenharia Civil, v. 4, n. 2, 2012.

NUNES, G.; LIMA, A. J.; MICHELAN, D. C. G. S. Remoção de Cor e Turbidez no Uso e Fibras de Coco Flexíveis e Areia como Meio Filtrante In: XI Encontro de Recursos Hídricos em Sergipe - ENREHSE, 2018, Aracaju. Anais [...]. Aracaju: Sergipe, 2018.

PERONI, B. L. CAMPOS, L.; SANTOS FILHO, P. R. A.; ALMEIDA, J. B. S. M.; GOMES, M. S. R. Extração do tanino a partir da casca de coco verde (cocos nucifera) e síntese do poliestireno sulfonado de copos plásticos. 
Brazilian Journal of Development, v. 5, n. 10, p. 21316-21330, 2019.

PFANNES, K. R.; LANGENBACH, K. M. W.; PILLONI, G.; STUHRMANN, T.; EURINGER, K.; LUEDERS, T.; NEU, T. R.; MULLER, J. A.; KASTNER, M.; MECKENSTOCK, R. U. Selective elimination of bacterial faecal indicators in the Schmutzdecke of slow sand filtration columns. Environmental Biotechnology, 2015.

RAJAPAKSE, J. P.; FENNER, R. A. Evaluation of alternative media for pebble matrix filtration using clay balls and recycled crushed glass. Journal of Environmental Engineering, v. 137, n. 6, p. 517-524, 2011.

SANTOS, F. F. S. Comparação entre os meios filtrantes areia e nãotecido sintético na eficiência da filtração lenta para tratamento de água. 2015. Tese (Doutorado em Engenharia Agrícola). Universidade Estadual de Campinas, 2015.

SANTOS JUNIOR, J. L., SANTOS, L. A. R., LIMA, A. J., MICHELAN, D. C. G. S. Tratamento de água por filtração lenta com meio filtrante composto de areia e resíduo sustentável de maravalha. In: XIII Encontro de Recursos Hídricos em Sergipe - ENREHSE, 2020, Aracaju. Anais [...]. Aracaju: Sergipe, 2020.

SILVA, E. J.; MARQUES, M. L.; VELASCO, F. G.; FORNARI JUNIOR, C. C. M. Degradação da fibra de coco imersa em soluções alcalinas de cimento e $\mathrm{NaOH}$. Revista Brasileira de Engenharia Agrícola e Ambiental, v. 19, n. 10, p. 981-988, 2015.

SILVEIRA, L. R.; COUTINHO, M. M. Utilização de filtro de múltiplas camadas para remoção de turbidez. Revista Tecnia, v. 1, n. 2, 2016.

SIMONETTI, R. H.; GUIMARÃES, M. S.; PINTO, J. S.; SILVA, M.; NAAS, I. A. Desenvolvimento de um equipamento para trituração de coco verde. Brazilian Journal of Biosystems Engineering, v. 11, n. 1, p. 3746, 2017.

SOUSA, F. W.; MOREIRA, S. A.; OLIVEIRA, A. G.; CAVALCANTE, R. M.; NASCIMENTO, R. F. Uso da casca de coco verde como adsorvente na remoção de metais tóxicos. Química Nova, v. 30, n. 5, p. 11531157, 2007.

SOUZA, F. H. et al. Study of slow sand filtration with backwash and the influence of the filter media on the filter recovery and cleaning. Environmental Technology, v. 37, n. 14, p. 1802-1810, 2016.

TANGERINO, E. P.; ARAUJO, L. M. R.; BORGES, R. M. Evaluación del desempeño de filtración en múltiples etapas usando carbón activado granular y mantas sintéticas no tejidas. Interciencia: Revista de ciencia y tecnología de América, v. 38, n. 10, p. 726-732, 2013.

TANGERINO, E. P.; DI BERNARDO, L. Remoção de substâncias húmicas por meio da oxidação com ozônio e peróxido de hidrogênio e FiME. Engenharia Sanitária e Ambiental, v. 10, n. 4, p. 290-298, 2005.

TERIN, U. C. Desempenho de coagulantes naturais, adsorvente alternativo e filtros lentos domiciliares no tratamento de águas com Microcystis aeruginosa e micorcistina: alternativas tecnológicas para comunidades isoladas. 2017. Dissertação (Mestrado em Hidráulica e Saneamento) - Universidade de São Paulo, São Carlos, 2017.

TUNDIA, K. R.; AHAMMED, M. M.; GEORGE, D. The effect of operating parameters on the performance of a biosand filter: a statistical experiment design approach. Water Science and Technology: Water Supply, v. 16, n. 3, p. 775-782, 2016.

VERAS, L. R. V.; DI BERNARDO, L. Tratamento de água de abastecimento por meio da tecnologia de filtração em múltiplas etapas - FIME. Engenharia Sanitária e Ambiental, v. 13, n. 1, p. 109-116, 2008.

VERMA, S.; DAVEREY, A.; SHARMA, A. Slow sand filtration for water and wastewater treatment - a review. Environmental Technology Reviews, v. 6, n. 1, p. 4758, 2017.

WWAP. Relatório mundial das Nações Unidas sobre o desenvolvimento dos recursos hídricos 2019 - Não deixar ninguém para trás. UN-Water, 2019.

ZHANG, C.; HE, J.; ZHENG, Z. Modelling nutrients and organics removal by biological slow filtration in micropolluted water source treatment. Processes, v. 6, n. 128, 2018. 